

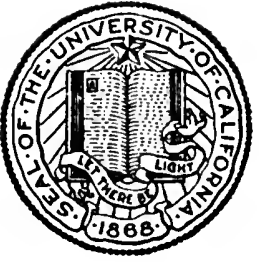

THE LIBRARY OF

THE UNIVERSITY OF CALIFORNIA LOS ANGELES 


$$
-
$$





\section{Insomnia and Nerve Strain}

By

Henry S. Upson, M.D.

Professor of Diseases of the Nervous System in the Western Reserve University, Attending Neurologist to the Lakeside Hospital, Cleveland, Ohio

\section{5}

With Skiagraphic Illustrations

G. P. Putnam's Sons

New York and London

Tbe knickerbocker press

1908 
Copraight, 2908

BY

HENRY S. UPSON

Tbe Enickerbocker press, Mew pork 
RC
602
$u 69$

A truth-four columns tottering, The more with each successive brick, until The key is added, then, foursquare and strong, The world may rest on it. 
Digitized by the Internet Archive in 2007 with funding from Microsoft Corporation 


\section{PREFACE}

$A$ MONG the insanities some groups due $A$ to changes in the organ of the mind are understood in course and nature. Others, called psychoses, aberrations that come alike to young and old, mysterious legacies, have all the terrors that attach to mystery and occur in forms of strange and violent contrast. Their ultimate cause is unknown; they are precipitated by physical and mental shocks and injuries varied in circumstance and fantastic and deplorable in their effects. Why these several causes should have one result, and results at times so varied be capable of springing from one cause is a question whose solution might carry with it chances of prevention and cure.

The test of a theory is its ability to explain observed facts. To fully prove a hypothesis all useful observations should be made and sifted, including those facts 
not previously observed because too familiar. The mass of these at times outweighs the other. An adequate theory should explain the origin of psychoses in these diverse and distant ways, make of the fantastic deeds and mad fancies of these unfortunates simple reactions to causes such as influence the lives of other men, and render definite the nature of such an undesirable heritage and the way of its transmission.

The present record was at first intended as in the main a contribution to observed facts. Circumstances have made of it an attempt at an interpretation of more familiar facts of wider range, with a few observations in the part of the field which happened at the time to be more nearly in the author's view.

It is useless to cherish illusions with regard to the present attitude of the medical profession and the public toward the psychoses. It is almost Mahometan fatalism. The neuroses are often curable by mental measures, the domination of the body by the mind, but even medieval 
sages and astrologers wasted few formulas over cases of insanity. The psychoses are a stone wall against which the waves of psychotherapy beat in vain. At most they wear away a little of the soft porous rock of the mildest of them, Hence the deplorable fact that so soon as a case is diagnosed as mania, melancholia or dementia precox, the patient is housed in an asylum, or at the very best, fed and tended by some loving relative, pending the execution of nature's sentence.

The doom of the patient lies inherent in the definition of his malady. So long as a psychosis is to the physician a disease without a lesion, sufferers from that dread malady of the soul will be given care with practically no treatment, pity with practically no hope.

No apology, then, is necessary for any attempt to look behind the veil. It hides disease so hopeless that from the more dread form, dementia, fewer of those afflicted recover, in spite of all that love and skill can do, than of sufferers from 
consumption or cancer or the black plague itself. Those who do not recover are found in our asylums, largely peopled with these unfortunates.

No attempt is made in this small work to collocate the material available for a study of the psychoses. Two objects only have been kept in view; to put on record a few observations as material for the reconstruction of a column long since fallen and neglected by recent workers in this field, and in what measure may now be feasible to supply that most solid of all building materials, a working theory to bind the swaying fabric of the structure. 


\section{CONTENTS}

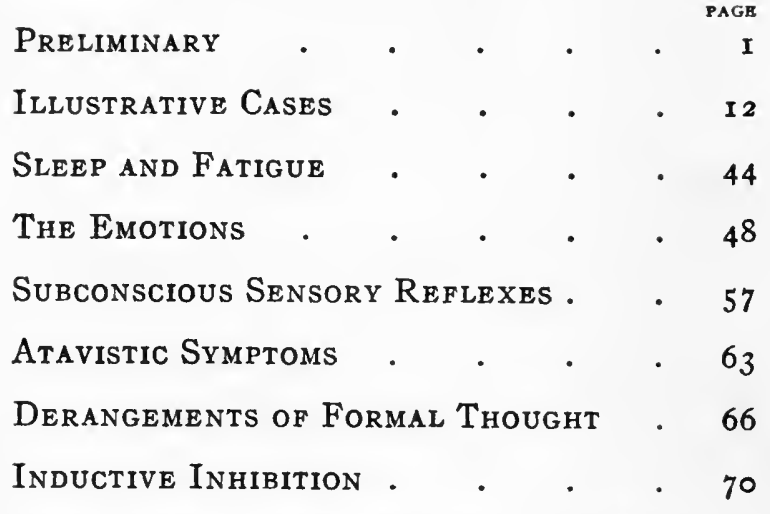

Convulsive Seizures and Choreic SPASM • • • . $\cdot 72$

Vascular Potential • • • . $\quad$ - 84 Mechanism of The Vaso-Neural Circult $\quad \cdot \quad \cdot \quad \cdot \quad \cdot \quad \cdot 94$

Nutrition and Vitality • • • 98

Cell Potential in Evolution • • 102

EPICRItic Neuro-Psychoses . ‘ . 105 


\section{Contents}

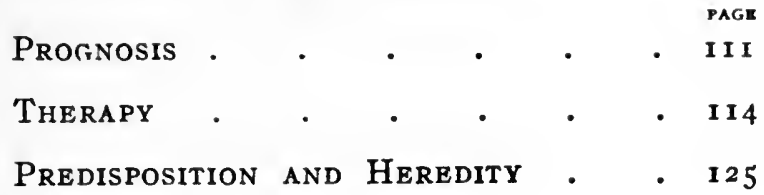
Appendix:

Dental Lesions . . . . $13 \mathbf{I}$ Technique of Dental Skiagraphy 139 


\section{ILLUSTRATIONS}

CASE 5.-Melancholia. Impacted upper left third molar

CASE I 4.-Hysteria. Impacted lower left third molar

CASE I 5.-Acute Mania. Impacted cuspid tooth

CASe I6.-Incipient Dementia Precox. Impaction of all of the wisdom teeth . I4

CASE I8.-Dementia precox. Impaction of a lateral incisor and all four wisdom teeth $3^{8}$

CASE I8.-Dementia precox. Upper right third molar

CASE 22.-Mania. Impacted lower third molar 
Case of profound melancholia, with subconscious sensory reflex in upper incisor teeth. Impaction of upper third molar.

Impacted upper fourth molar tooth .

Case 2.-Insomnia. Alveolar abscess. Lower molar tooth. Roots partly absorbed . I $^{2}$

Case 3.-Renal and Vascular Disease. Multiple abscesses in both upper and lower jaws.

CASE 4.-Melancholy. Alveolar abscess. Molar tooth. Roots partly absorbed . I32

Case of Albuminuria with cardiac and vascular symptoms. Complete nervous breakdown of five years' standing. Multiple abscesses in both upper and lower jaws . $\quad 1^{2}$

Position for upper right molar region. Tube and film should be placed well back. (Dr. Lodge.)

Position for lower right molar region. (Dr. Lodge.) 


\section{Illustrations}

xiii

FACING

PAGE

Position for upper incisors. (Dr. Lodge.) $\mathbf{I}_{4} \mathbf{2}$ (Third.)

Position for lower incisors. (Dr. Lodge.) I 42 (Fourth.) 



\section{INSOMNIA}

\section{AND NERVE STRAIN}

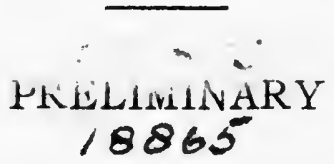

$W^{\text {ITH regard to the nature of the }}$ pathologic processes underlying painful and other functional nervous and mental disorders, authorities are at the present day practically unanimous in ascribing them either to those most misty of all indefinite conditions, nervousness, hysteria, and autosuggestion, or to toxins of unknown origin and uncertain nature.

\section{Physical Causes of Insanity.-} Among the physical causes of insanity diseases of viscera other than the brain formerly held a prominent place, the 
2 Insomnia and Nerve Strain

mind and the soul in medieval thought being considered to reside in the entrails. With the growing realization of the importance of the brain as the soul and mind organ, the tendency gained ground to regard insanity as a brain disease, and to limit its causes to psychic shocks and brain lesions. In spite of this fact diseases of many of the viscera have held their place, although a subordinate one, even in the text-books of to-day.

Patients affected with phthisis and with heart disease in their late stages, have long been known to become in some instances the victims of atypical psychoses. Affections of the digestive system and of the pelvic organs are recognized as more frequent causes of insanity, and the kidneys and liver, thyroid gland, and practically all of the other viscera are known to be the occasional seat of changes which cause mental alienation. Many cases recently described by Suckling, of London, show the importance of movable kidney as a cause of various 


\section{Preliminary}

forms of insanity, especially mania and melancholia.

Dental Disease.-Cases long ago reported were regarded as showing that even disorders of the teeth might in rare instances cause insanity, and early in the nineteenth century Esquirol, the great French alienist, stated that the first dentition by causing convulsions in children predisposes to insanity, and that tardy appearance of the teeth sometimes causes it.

In 1876 the English alienist, Savage, reported a number of cases of insanity terminating by acute illness; among them that of a man of twenty-two, of bad heredity, who became maniacal, rode madly about the country, was unmanageable, and brought to the asylum. After three or four months he developed a severe toothache which he endured for a few days and the tooth was then pulled. There was pus at the ends of the roots. The patient recovered promptly from his mania. Another patient reported by 


\section{Insomnia and Nerve Strain}

Savage recovered from mania after the development and evacuation of an alveolar abscess. These are mentioned by Lauder Brunton in an essay as cases of insanity due to diseased teeth.

Similar cases have been reported from time to time, and lesions of the teeth find occasional mention in some of the older text-books of mental disease. Dental works still speak of insanity and many other functional nervous disorders as occasionally due to dental lesions. Modern psychiatry takes no account of these scattered cases, and I am not aware that any one has ever looked for dental disease as a cause of insanity, or attempted a cure by its eradication.

There seems to exist among physicians not only a disregard but a distinct though mild dislike of the teeth as organs to be reckoned with medically, they being as it were an Ishmael, not to be admitted to their pathologic birthright. Lauder Brunton's essay on the subject is too little known and heeded, and few such 
systematic attempts have been made to correlate their disorders with the sufferings of the human race, except for the most obvious phenomena of pain. Ordinary pain at a distance, as headache or neuralgia due to the teeth, though well known is commonly disregarded. Even the various reflex nervous phenomena in children, convulsions, fretfulness, and fever, are not now ascribed to the irritation either of teething or of dental caries, but to digestive disorders. The state of recent opinion as enshrined in epigram is that the result of teething is nothing but teeth.

Dissociation of Symptoms. - The present attempt at a study of the sensory phenomena of dental lesions had its fons et origo in an observation made in a case of ordinary toothache that the depression and insomnia did not vary in direct ratio with the pain, but were sometimes marked when the local pain was slight. The symptoms being thus discovered to be dissociated phenomena, the disjecta 


\section{Insomnia and Nerve Strain}

membra of a symptom complex, a provisional theory was formed subject to correction by further study, that toothache is no more the cause of insomnia than is this the cause of the ache, but that both are in equally direct dependence on the dental lesion. In view of the possibilities thus raised the demonstration of the independence of all the concomitant symptoms of dental lesions seemed to acquire importance, and an investigation was entered upon, at first of cases of melancholia, and later of mania and dementia precox, with this point in view.

Incidence of Dental Lesions.-The occurrence of the commoner lesions, caries and abscess, can hardly be considered to have much significance without a study of the effect of their removal on the course of the disease. It was early apparent that a rarer condition, dental impaction, was relatively common in these patients. Of about fifty-two cases examined in the Cleveland, Massillon, and Columbus State Hospitals, through the courtesy of their 


\section{Preliminary}

respective superintendents, twenty-five patients were suffering from impacted teeth, many of them having several lesions of this kind.

To make a test of the ultimate value of the relief of this condition, on patients insane, many of them for long periods, and many demented, must be the work of some years. Meanwhile the cases seen in private practice, most of them of shorter duration, many suffering from the milder dental lesions, have presented some points of interest and have seemed worthy of collocation with cases, seen during the past fifteen years, of neuroses and psychoses due to disease of other viscera. The surprisingly frequent dental irritations in a way supplement these others, and stop a gap both diagnostic and therapeutic in the study of the nervous results of visceral lesions. To this fact is largely owing what may seem an undue preponderance in number of dental cases cited.

The main theme of the present work is a provisional sketch of the mode of origin of the psychoses. An early presentation 
is made in the hope that others may be induced to consider the field a promising one for further study.

Head's Researches.-It is necessary first to consider the general features of the sensory system in order to appreciate the possibilities of the genesis in it of emotional and mental disease. Fortunately the study of the afferent nervous system published by Head, Rivers, and Sherren in Brain, November, I905, renders this possible.

In order to make a thorough investigation of conditions in the parts of the skin supplied by peripheral nerves, Dr. Head caused the radial and external cutaneous nerves to be divided in the neighborhood of his own hand and elbow and afterwards subjected his arm and hand to systematic examinations. The result was the discovery of three distinct forms of sensibility, the first of which he calls deep sensibility, supplied to the deeper structures by afferent fibres running with the motor nerves. The result of pressure is 


\section{Preliminary}

pain which is fairly accurately localized. This function persists after the cutaneous nerves of a part have been thoroughly divided.

The skin is found to possess two forms of sensibility, one the epicritic, by which one appreciates light touches localized with considerable accuracy, and impressions of warmth and coolness.

The other form of sensibility is called by Head protopathic. It is deeper in 1ocation than epicritic sensibility, not being evoked by light touches but by comparatively deep pin-pricks or by heat or cold or touching or pulling hairs. It is peculiar in giving a sensation that when intense is a distinct pain, not well defined but widespread and radiating. When located it may not be at the point stimulated but at some distance.

Protopathic sensibility is recovered sooner than is the epicritic variety, and with this recovery trophic changes consequent on division of the nerves disappear. Recovery of protopathic function 


\section{Io Insomnia and Nerve Strain}

in Head occurred in seven weeks, and was complete in twenty-nine weeks, while the epicritic fibres were not fully restored a year after the operation.

After the protopathic fibres had recovered their function and while epicritic sensibility was still lacking, it required a stronger stimulus than normal to cause pain, but the response was excessive and was accompanied by an irresistible impulse to draw the hand away. This indicates a certain amount of control of the protopathic by the epicritic system.

Visceral Sensibility.-Sensibility of the viscera corresponds very closely with that supplied by the protopathic system to the skin. Their nerve-supply must be regarded as a part of the same mechanism. Head found that heat and cold, when applied within the walls of the intestines, were said by patients to be uncomfortable, but the sensation was never localized in the abdomen. They gave a burning or cold feeling, sometimes on the 
skin and sometimes in the air entirely outside the patient's body.

In the viscera deep sensibility seems to be subserved by the end-organs of Pacini and probably gives some indication of movement and position.

It is evident from Head's researches that the epicritic system is mainly concerned with localization and the representation of sensation in consciousness, that is to say, in the cortical receiving centres. The deep and protopathic systems supply information that is often dim and may not be present in consciousness at all.

In investigating the relations existing between disorders of sensation as they affect emotion and mentality in functional nervous disease, it has not been possible to separate the deep and the protopathic systems. The relations of the epicritic system with regard to the other two are more clear, but throughout this work when the protopathic system is spoken of it may be taken to include the deep system. In the same way the epicritic and voluntary functions of the 


\section{Insomnia and Nerve Strain}

cortex are distinguished with comparative ease from those of the lower centres, but when basal ganglia are spoken of they are meant to include not only the ganglionic masses at the base of the brain, but the spinal cord as well.

Irritative Theory of the NeuroPsychoses.-The view here taken of the neuroses and psychoses in general is that they are primarily irritative disorders of the sensory system affecting the remainder of the nerve mechanism indirectly. The irritants are either mechanical or toxic, and the discussion of their location and mode of action may be deferred until later.

\section{ILLUSTRATIVE CASES}

Among the diseases to which mankind is subject dental caries is probably the most common, and of dental caries and other disorders of the teeth insomnia is, I believe, much the most common symptom, often occurring without local pain 
or indication of its place of origin. It is usually accompanied by other indications of disordered nerve-action. The following case is among the more simple instances.

Case I. Insomnia.-The patient was a young business man thirty years of age previously in good health. When seen he had been suffering from persistent sleeplessness without obvious cause for about a year. $\mathrm{He}$ had been working hard but was under no financial strain, and had simply noticed an increased difficulty in going to sleep and tendency to waken after a few hours. He drifted into the habit of taking the usual hypnotic drugs, felt rather weak and nervous during the day, and was quite unable to work. He was unusually sensitive to noise and light.

Skiagraphs of his teeth showed no lesions with the exception of a number of cavities, one of which affected the pulp-chamber. Convalescence began before his dental work was finished and was 


\section{Insomnia and Nerve Strain}

continuous so that within a few weeks he was sleeping well without narcotics.

Neither in this nor in any other of the dental cases has there been toothache or other localizing symptom referable to the teeth except as noted. J

Case 2. Insomnia.-Insomnia is so constant a factor in the life-history of many people as to be considered constitutional. These cases, however, are on a basis of distinct physical disease. One patient recently seen, a man sixty years of age, has for the last thirty or thirtyfive years had more or less insomnia, lately consisting of an early wakening usually at about four o'clock. During the earlier years of his life he was sometimes persistently sleepless for long periods without pain or obvious cause. Skiagraphic examination showed a condition of the teeth dating back to a beginning many years ago. Two of the teeth were set in pus pockets, very loose, and had at times been ulcerated. Two 


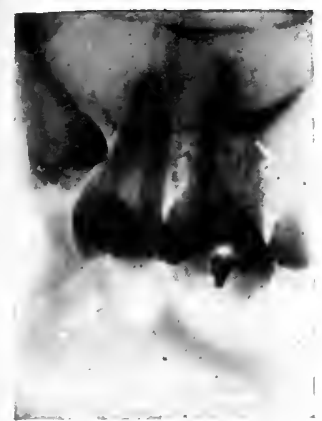

CASE 5.-Melancholia. Impaced upper left third molar.

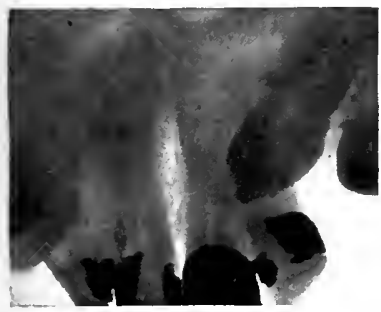

CASE I 5.-Acute Mania. Impacted cuspid tooth.

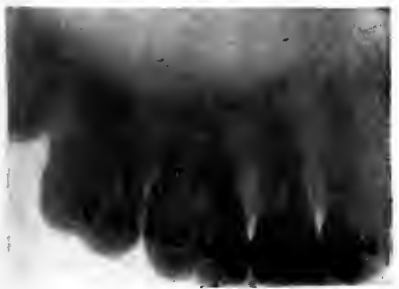

CASE r 6.- Incipient Dementia Precox. Impaction of all of the wisdom teeth. One upper and one lower impacted tooth are here shown. 



\section{Illustrative Cases}

of the other teeth had abscesses at the roots. The two teeth most diseased were drawn and the others treated. The patient has since been sleeping through the night without wakening, for the first time in many years.

Case 3. Insomnia: Arterial Disease. -One of the complications of insomnia which is of more than usual importance is arterial disease. Worry and other emotions are thought to create arterial tension as an important factor in causing arterio-sclerosis. The underlying physical element which exists in many such patients is illustrated in the following case.

A business man sixty-five years of age began six years ago to suffer from insomnia consequent, apparently, on worry over his financial affairs. For more than two years he suffered from marked insomnia and great mental anxiety and then broke down in health. He had a slight stroke of paralysis, suffered much with bad feelings in his head of an indefi- 


\section{I6 Insomnia and Nerve Strain}

nite character but without local pain. An examination of his teeth showed that they were in very bad condition and skiagraphs revealed multiple abscesses in both the upper and lower jaws. Extraction of some of the teeth was followed by marked relief, but the case remains incomplete therapeutically.

Case 4. Melancholy.-Equally simple and common are the cases of melancholy running into mild melancholia with somewhat perverted introspective ideas rather than genuine delusions. Of this a typical example is the following: A wealthy man thirty-five years old, with no business cares, has had for the last twelve or fifteen years occasional attacks of depression lasting from two or three to ten or twelve months. When first seen he had been depressed for several months, thought that he could not recover and considered himself a nuisance to his family. He had had no pain of any kind. During some of these attacks sleep had been disturbed, but when seen he 


\section{Illustrative Cases}

was sleeping well and had a fairly good appetite. Skiagraphs showed irritation at the roots of a few of the teeth and an abscess at the roots of one molar tooth, which was treated for some time but finally had to be drawn. He made a progressive and rapid recovery.

Case 5. Insomnia: Melancholy.A somewhat whimsical element is introduced into the following case by the psychic cause, although the symptoms, except for their short continuance, were of a much more serious character.

A robust mechanic twenty-eight years of age, three weeks before he was first seen came home from his work, and his wife moodily remarked that she thought she was losing her mind. It immediately occurred to him that he might be losing his mind. He slept little that night or the succeeding nights, gave up his work and spent his days in fear of the asylum. In brief, tonics and assurances failed to relieve. The only discoverable lesion was dental caries, and the filling of a deep 


\section{I8 Insomnia and Nerve Strain}

cavity extending into the pulp was followed by prompt recovery and return to work. There had at no time been toothache or other pain, but dizziness and sweating had been noted.

Case 6. Insomnia: Melancholia.Such cases as the above merge gradually into typical melancholia of the profounder kind. An unmarried woman, twentyseven years old, a teacher, for a year had been profoundly melancholy with intractable insomnia, delusions of various deadly sins, and entire hopelessness of recovery. Restlessness was extreme, tonic and local uterine treatment were of no avail. As a last resort the teeth were examined. They were apparently in perfect condition. A skiagraph showed an impacted right upper third molar tooth pressing against the second molar, a condition obviously capable of causing irritation. The symptoms, in about a week after the removal of the tooth, began to improve. Recovery was complete in six or eight weeks, and has 


\section{Illustrative Cases}

persisted. There had been at no time pain or other localizing symptom.

The investigation of dental conditions early in its course took more definite shape in the examination of the third case observed, through the advice given by Dr. John F. Stephan, to have skiagraphs taken of the teeth in order to a thorough elucidation of the conditions. The examination of the first patient by skiagraph showed negative results. The recovery of the second patient took place by dental treatment without skiagraphic examination. In the third patient, however, the teeth on inspection seemed to be in unusually good condition but an impacted third molar tooth was present and its removal was followed by recovery from melancholia. This is the case just cited in the present series.

Case 7. Melancholy of Dental OrIGIN.-In this connection Dr. Stephan imparted to me the following interesting observation which he had previously 


\section{0 \\ Insomnia and Nerve Strain}

made. A patient in whom suppuration was present at the roots of one of the teeth was subject to a depression which seemed to her like a cloud enveloping her. On opening the tooth the cloud lifted. When the tooth was closed there invariably followed within about an hour a settling down of this emotional cloud, even when the patient supposed that the tooth had simply been treated but not olosed. The result was invariable on several trials so long as the abnormal dental condition persisted.

Case 8. Melancholia.-Emotional variations which accompany disorders of the abdominal and pelvic viscera are so common as to be matters of daily observation. It is of special importance to realize that there is no essential difference between mild cases of this character and the severer cases of melancholia and mania which, due to the same cause, present all of the mental symptoms characteristic of what are considered true psychoses. The clinical picture of agitated 


\section{Illustrative Cases}

melancholy is, in my experience, often met in connection with gastric and intestinal disease. Mild melancholy is an almost regular accompaniment of indigestion, and this under exceptional conditions may rise to a condition of frenzied depression with intractable nervousness and insomnia.

One such patient, a man sixty-three years of age, in whom the attack of mental alienation followed dysentery, responded readily and rapidly to purgation, milk diet, and the salicylates, when hypnotics and sedatives were powerless to give more than the slightest relief. In this case, insomnia, agitation, and depression were extreme, and the symptomatic diagnosis of melancholia agitata was amply justified by the conditions present.

Case 9. Melancholia.-The cause in the preceding case was obviously physical. In the following instance the exciting cause was psychic, so purely as almost to exclude the probability of a physical 
basis. The patient was a woman, fiftyfive years of age, fat, florid, and always in perfect health. Three months before she was first seen, her husband accidentally shot himself and she was in consequence much alarmed and agitated. The wound proved to be a slight one, but she found herself depressed in spite of this fact, and during the whole intervening time until I saw her she was sleepless at night, heavy and depressed by day, and was firmly convinced that she was insane and would be sent to an asylum. Little could be made out with regard to the abdominal organs on account of the layer of fat. Physical examinations gave negative results. The only apparent anomaly was loss of appetite with moderate flatulence. However, on milk diet, laxatives, and intestinal antiseptics, sleep promptly returned without hypnotics, although these, even in rather large dosage, had previously failed to relieve. She made a progressive recovery.

Case io. Melancholia.-The follow. 


\section{Illustrative Cases}

ing case is in appearance simple. Psychic shock was followed by a digestive difficulty as the physical basis of disordered function. The patient was a man forty-two years of age who in general had been in good health. Some four years before he was seen he went through a period of business anxieties. He was also overworked for several years and finally began to notice that he was unable to work as well as usual. He became depressed and anxious and had a definite feeling of sinking in the epigastrium. He had no ringing in the ears or tingling in the hands, but had a full feeling in the head with more or less throbbing. No especial examination was made at that time for dental lesions and in this respect the case remains obscure. Periods of very great depression would come on, lasting for some hours, and would then pass off, leaving him comparatively free, although far from well. His paroxysms of depression were apt to come soon after meals. In a few months they were partially replaced by attacks of intolerable 


\section{Insomnia and Nerve Strain}

itching. This came quite irregularly, sometimes several times a day and sometimes not for a week or two. They lasted from one to twenty minutes. His back and the backs of his hands were the parts most affected. This itching was at times accompanied by a red rash along the front of the arms, which was called urticaria by the physicians who saw it. The patient describes it as an itching which did not incline him to scratch, but was like a prickling sensation as of needles stuck through the skin from within out. All sorts of applications were powerless to relieve this condition. It was diagnosed as an affection of the vaso-motor nerves by every physician who saw it. Baths and many forms of medication were tried without effect. The patient was seen by many eminent practicians and specialists. Meanwhile the continual worry and depression were present, but somewhat better.

Two years after the beginning of the disease, the patient himself insisted on a chemical examination of the stomach 
contents. A slight subacidity was found, attributed by the examining physician to nervous dyspepsia. He prescribed seven drops of dilute hydrochloric acid, but said at the time that it would probably not be effectual in relieving the symptoms. It is significant that the attacks of itching were always accompanied by psychic pain, with a feeling of tension in the frontal region. The patient would then have an inclination to sleep, and would awake feeling much refreshed.

The very first dose of hydrochloric acid was followed by complete relief from both the itching and the psychic pain. The acid was taken two or three times a day for six weeks and ever since that time it has been taken when needed. It is invariably effective and there has never been a return of very severe itching. Some attacks of depression have occurred so that several times the patient has felt as if he might have to give up his work. On taking the acid, however, for a few days he has invariably recovered from this feeling. 
26 Insomnia and Nerve Strain

Certain things have disagreed with the patient. $\mathrm{He}$ thinks that sweet things-eggs, milk, and in general things which make him feel bilious - are to be avoided. The patient has now been in good health for thirteen years.

Case it. Melancholia.-The following is a case common enough in its essential features but too often unrecognized as regards the physical substratum. The patient, a woman thirty years of age, took up an amount of mental work that involved moderate overstrain. Although at the time she was in unusually good health, she soon began to be sleepless and depressed, and developed delusions that she was pregnant and that she had committed various unpardonable sins, and procured a revolver with a view to committing suicide. When seen she had grown steadily worse for two or three months. She had the usual coated tongue and pallor of the melancholic, tired easily, had no energy, and was much occupied with her delusions. Examina- 
tion revealed serious disease of both uterus and ovaries. Great improvement in the mental condition was apparent within a few days after an operation undertaken to relieve the pelvic conditions. The patient gained steadily in strength and cheerfulness for about a year, and is now, six years after the operation, in good health.

Case i2. Melancholia.-The following history is communicated to me by Dr. Humiston, who rescued the patient after some months of asylum residence. She was seen by me for the first time during her convalescence. The patient, a woman thirty-five years old, became profoundly melancholy after the birth of a child. She thought her own soul and those of her immediate family lost through her fault. The onset of her illness was quite acute, with a severe headache forty-eight hours after the birth of the child, and was attended with intense agitation and sleeplessness. She had no pain, but complained that her head felt as if 


\section{Insomnia and Nerve Strain}

it had been split open and her soul extracted.

The uterus, which was much inflamed and in a fibroid condition, was curetted and fixed in normal position. Between three and four weeks after the operation the patient was discharged from the Hospital, cured physically, and much improved mentally. Although more cheerful she still suffered from delusions. Recovery, however, was uninterrupted from this point, and the patient has remained in good mental health and great physical vigor for twelve years.

Case 13. Neurasthenia.-The association of neurasthenia with varied diseases of the abdominal and pelvic viscera is significant. Such patients as the following are common and persistent apparitions in the waiting-room. The patient was a woman forty years of age. She was fairly well until the birth of her first child some years ago. After that time she had a great deal of trouble with her stomach, had to be careful of her 
diet, and suffered a great deal from backache and headache. For three or four years she spent most of the time in bed and was much weakened and emaciated.

Her menstruation was regular and not especially painful but it was attended with considerable prostration. For six or eight months before she was first seen she had been in bed continuously, and was eating only eggs, broiled beef-steak, and dried bread. She had attacks of distress in the stomach and a distinct drawing feeling from the stomach to the head. These feelings were relieved by taking food, which she did quite frequently. The predominant symptoms, however, were purely nervous, great sensitiveness to physical and psychic shocks and proneness to fatigue, giving her illness the unmistakable impress of the fatigue neurosis of gastro-intestinal type.

The patient was miserably emaciated and weak but not anemic. The abdominal organs appeared normal, the tongue slightly coated; the pulse eighty, soft and 


\section{Insomnia and Nerve Strain}

regular. The urine contained a slight amount of albumin but no sugar and no casts. The specific gravity was 1.026 .

Gastric hyperacidity was diagnosed, and marked relief followed the frequent giving of bicarbonate of soda in large amounts. Radical cure, however, was only obtained by curetting the uterus and removal of both ovaries, which were badly diseased. This was successfully carried out by Dr. W. H. Humiston, to whom I am indebted for constant cooperation in this and other similar cases. Recovery was slow and the management of the case difficult. The patient has now been in good health for more than ten years.

Case i 4. Hysteria Minor.-While hysteria major comprises cases presenting certain definite and severe symptoms, hysteria minor is a vague term applied to a great variety of conditions. The following case, communicated to me by a colleague,might be considered hypomania, but corresponds more nearly with the 


\section{Illustrative Cases}

conception of a severe but not major attack of hysteria. The patient, a young married woman twenty-five years of age, rather suddenly, in November, I907, developed fearful pain in her head with attacks of hysterical screaming. She began to be very nervous and sleepless, cried easily, and lost weight rapidly. On the 3 oth of December an impacted lower third molar tooth was removed. On the I 7 th of January, r 908 , she was better in other ways but the screaming attacks continued. She was given bromids and frequent nourishment. Improvement began on this regimen, and at about this time pain developed in an upper incisor tooth. An abscess was discovered and the tooth removed. The screaming attacks stopped at once and she has since been perfectly well.

Case I 5. Mania.-The excited phase of the manic-depressive group is well represented by the following fairly typical case of acute mania. The patient was a physician, twenty-eight years of 


\section{Insomnia and Nerve Strain}

age, first seen a week after the maniacal condition was first noticed. $\mathrm{He}$ had overworked for the last year or two and for a time had been sleepless, but it was not possible to ascertain exactly how long. Otherwise he was considered well. During the preceding week, however, he had acted in a peculiar way, laughing and talking foolishly but insisting that there was nothing the matter with him. For some weeks he had complained of moderate pain in one of his teeth. When seen he was rational but inconsistent and foolish in his talk and somewhat incoherent. By skiagraph the right upper first bicuspid tooth was found badly impacted and was drawn. For a week or ten days he was unmanageable, but then began to quiet down, slept well, and has gone on to a progressive recovery.

Case i6. Incipient Dementia Precox. - The preceding case might be apprehended as one of beginning mania or of dementia precox. The two conditions merge into each other, and the diagnosis 


\section{Illustrative Cases}

in such a case is of prognostic but not theoretical importance. The following case, however, is one of a somewhat different character. Though it might at first sight seem mild, its manifestations have the importance which attaches to patients who are mentally affected but hardly in condition to be sent to a hospital.

The patient is a bright boy of sixteen, the son of an unusually intelligent professional man. Until a year before he was seen he was well, of a bright, cheerful disposition, and a general favorite. This was with the exception, however, of very moderate nervousness and some frontal headache during the last two or three years. During the last year his disposition changed. He became somewhat morose and irritable, and showed less affection for his family and friends than before. He was increasingly nervous and restless so that he could not sit or read long and only had four or five hours of sleep during the night. He also had practically constant frontal headache and a severe feeling of oppression 


\section{Insomnia and Nerve Strain}

in the occipital region, but no neuralgic or dental pains. He was often dizzy, especially when he bent his head. Being athletic and strongly built he suffered from a good many kicks and blows on the head in playing football. The right occipital region was somewhat sore to pressure and on pulling the hair.

On skiagraphic examination all four of the molar teeth were found impacted. The left lower third molar was extracted first, and the feeling of pressure at the back of the neck immediately disappeared, and from that time on sleep was somewhat better. The upper third molar teeth were extracted three weeks later, and on the night following their extraction he slept soundly for ten or twelve hours. After this he slept well every. night, but within a few weeks became restless once more and the bad feelings returned to his head. The right lower third molar tooth was then extracted, and the head pains were once more relieved. Sleep has continued good, the patient has gained in weight steadily, 


\section{Illustrative Cases}

has had a good appetite, felt quiet, and his family have noticed a marked change in his demeanor. $\mathrm{He}$ has regained his affectionate bearing toward them.

In writing of him recently his father said: "We noticed a great change in John's conduct compared with that previous to the time when you first saw him. This became more noticeable after the last extraction. He has been gentler, more tractable, affectionate, regular in his habits, and more natural in every way. I think that physically he has been much weaker than six months ago. I suppose the nervous shock incident to the operations may account for that. Though less nervous and excitable, he tires with the least exertion and requires a great amount of sleep. His appetite has increased every day. He has not had any desire for tea, coffee, or hot drinks, but is perfectly satisfied with cold water."

With regard to the weakness noted in 


\section{Insomnia and Nerve Strain}

this case, it is a common sequel of the removal of a mechanical stimulus. The restless expenditure of energy is replaced by languor, and the exhausted ganglion cells should be given a good many months of repose before being called on for much exertion.

Case i 7. Incomplete Dementia Precox.-The importance of peripheral irritation in the members of the community whomGrasset calls theSemi-insaneand the Semi-responsible, suggested in the above case, is also of interest in the following recital of his life-experience given to me recently by a friend in the legal profession. The subject of this little autobiographic sketch is now forty-three years old. $\mathrm{He}$ says he was always difficult to manage at school, but was well, robust, and muscular. When he was a boy he had a controversy with a teacher and left school at the age of sixteen. At that time he struck out for himself. He then suffered for ten years from an uncontrollable impulse to wander. $\mathrm{He}$ 
began also to have neuralgic attacks, sometimes on one side of the face and sometimes on the other. These persisted for ten or twelve years and then ceased. Pain was severe in the third molar region, especially in the lower jaw on the right side, and there was pain in the other teeth, both upper and lower, and pain in the face. Drugs failed to control the pain, even a grain of morphin being quite useless. The left lower first molar was extracted when the patient was thirteen years old, and this seems to have removed the pressure from that region for no pain was felt in the lower jaw on that side. Between the ages of eighteen and twenty-five he had occasional attacks of moderate depression. The patient's wandering was all over the country, mainly, however, in the west, and was usually by bicycle or train, but when he was out of money he beat his way on freight trains. During the last fifteen years or so the impulse to wander has not been irresistible, but the patient travels when it is convenient. He has been 


\section{Insomnia and Nerve Strain}

able to study his profession and engage in successful practice.

Case i8. Dementia Precox.-The next case is one of typical hebephrenia. The patient is a girl nineteen years of age who was never very strong but not especially nervous. In February, 1907, she began to be low-spirited, cried frequently, and was afraid that she would lose her mind. Her hands and feet began to be cold, and she was especially depressed and weak before her menstruation. In June she began to talk of religious matters, prayed, and expounded the Scriptures. During July and August she talked, sang, and played on the piano incessantly, was excited and very contrary. In September she was better, but early in October ran out into the street and tried to escape. Since then she has torn her clothing whenever it was possible, has bitten and scratched her relatives, and been resistant and often angry. She has been persistently sleepless throughout her illness. She has had 

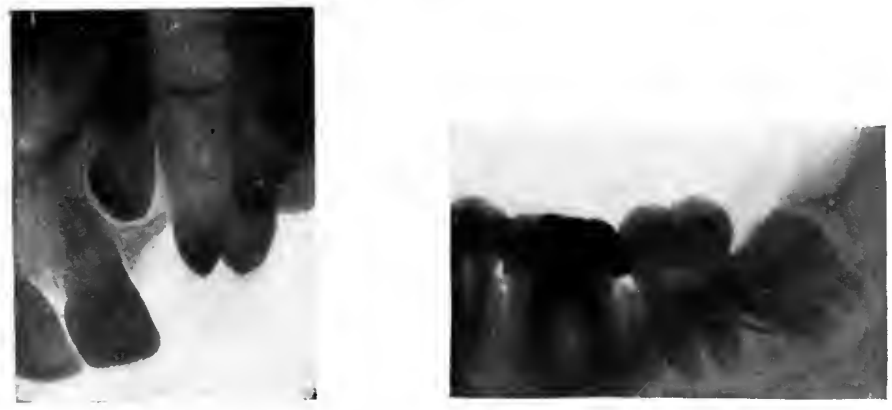

CASE I 8.-Dementia precox. Impaction of a lateral incisor and all four wisdom teeth. The incisor and one lower third molar are shown above.

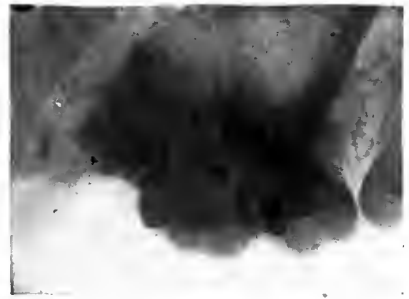

CASE I8. Dementia precox. Upper third molar.

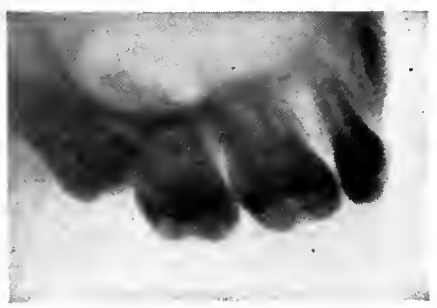

Case of profound melancholia, with subconscious sensory reflex in upper incisor teeth. Impacttion of upper third molar.

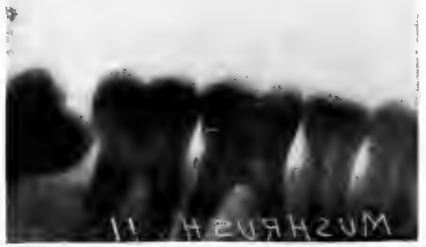

CASE 22.-Mania. Impacted lower third mclar.

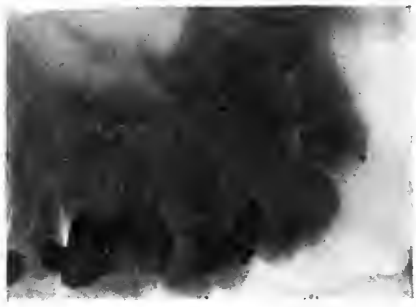

Upper fourth molar tooth. 


\section{Illustrative Cases}

no pain of any kind, neuralgic or otherwise, and has often said that she wished she had pain. During the latter part of her illness she kept her hands to her head and neck, a part of the time moaning, and trying to escape. She was pale, emaciated, and had the drawn, haggard look of many such cases. There have been cases of insanity in the family.

When seen in October it was suggested that, as an examination of the pelvic organs and of the teeth was impossible without an anesthetic, skiagraphs be taken under ether, a vaginal examination made, and any necessary operative procedures undertaken at once. After two months' delay, as her condition remained unimproved, this was done. Skiagraphs developed at once showed impaction of all four of the third molar teeth and of the right upper lateral incisor. The pelvic examination showed moderate retroversion, but no pelvic lesion adequate to account for the symptoms. The second molar teeth in the lower jaw were extracted to allow the removal of the 


\section{Insomnia and Nerve Strain}

third molars impacted against them. The third molar teeth were all removed, as were the right lateral incisor and one of the teeth against which it was impacted, the right cuspid tooth. For some days after the operation the patient was rather more restless. Then she became quieter, and it was noted that she put her hands to her neck and head less often than before. Her hands and feet were warm. She began to sleep rather better. From this time on she gained in weight and strength, her color was better, and hypnotics were soon discontinued. Of late screaming fits have developed. Although much of her improvement has persisted, her case is incomplete, and a year will probably be necessary to determine the result.

Dr. O'Brien's Cases.-For the following cases I am indebted to Dr. John D. O'Brien of the Massillon State Hospital. They are of recent observation and are selected as examples of what may be expected among the more imme- 
diate results of investigation and treatment of dental lesions, the first of the cases having been examined by skiagraph in October, I907. Dr. O'Brien has many other patients at present under observation for further study.

CASE ig. Mania.-The first patient is a robust young man, eighteen years of age. He was admitted to the Hospital in the excited phase of a first attack of manic-depressive insanity. He was irritable, destructive, and rather profane. There were found an impacted left lower third molar tooth and an abscess with impaction of the right lower third molar. Extraction of the affected teeth was followed by recovery in a few weeks and the patient has been discharged.

Case 20. Mania.-The second patient was also in a first attack of mania, excitable, pugilistic, destructive, filthy. There were found an impacted left lower third molar tooth with abscess formation, and also a large abscess at the base of a 


\section{Insomnia and Nerve Strain}

filling in another tooth. Extraction has been followed by amelioration of most of the mental symptoms.

Case 2I. Mania. - The third patient, twenty-five years old, was also in a typical maniacal condition, having had one such attack previously. There were found an impacted third molar tooth, an irregularity and projection forward of the upper incisor teeth with great displacement and a right upper second molar tooth impacted at right angles. Extraction was followed by marked mental and physical improvement, and the patient is practically ready to leave the Hospital.

Case 22. Hypomania. - The next case was one of a first attack of hypomania in a man twenty-five years old. A left lower third molar was found impacted. Recovery followed extraction very promptly and the patient has since been discharged.

Case 23. Dementia Precox.-The 


\section{Illustrative Cases}

fifth case was one of dementia precox of the katatonic form, in a young man twenty years old. There were found impaction of a left upper third molar tooth and impaction of a right upper third molar with abscess formation. Recovery followed extraction.

Case 24. Melancholia.-The sixth case was one of depression with marked suicidal tendencies in a man twenty-four years of age. He had never complained of his teeth. Skiagraphic examination showed an abscess involving the second and third molars of the upper jaw on the right side. Extraction was followed by recovery and the patient has been discharged from the Hospital.

Case 25. Melancholia. - The seventh case was one of depression with marked emaciation in a man forty years of age. In this case there had been a previous attack of hemiplegia. Multiple abscesses were found in the upper jaw. Recovery followed extraction of the 


\section{Insomnia and Nerve Strain}

teeth and evacuation of many pockets of pus.

\section{SLEEP AND FATIGUE}

Insomnia.-Insomnia is a symptom rather than a disease, and although it is not invariable in the neuro-psychoses it may be considered as practically the recurring link which binds them together. In order to understand the phenomena of insomnia, it is necessary to make at least a tentative definition of sleep.

Whatever else sleep may be, it must be mainly unconsciousness, though not alone a modification of cortical function. This is attested by the fact that the cortical centres of memory sometimes continue their activity during sleep and that the motor and even the perceptive centres are active in somnambulism. The negative element of sleep, rest through inactivity, is possible in varying intervals to all the tissues of the body. The active part of the process is peculiar to the brain, which shares the inactivity and 


\section{Sleep and Fatigue}

adds disjunction of the higher from the lower ganglionic levels in degree varying with the profoundness of the sleep. Thus comparative rest is compatible with waking. Considerable activity may go on in the dormant condition, but this activity contains a relatively small amount of interchange between the ganglionic levels.

The subjective element of insomnia is necessarily the conscious activity of the cortex. The natural inference is that sleep is banished because the cortical processes of perception and thought go on. An objective study, however, of cases of insomnia shows clearly its frequent dependence on the activity of the lower centres. Comparison of the cases just cited discloses the fact that protopathic irritation is accompanied by insomnia in the majority of instances. If the patient makes his insomnia an object of study he very often finds that wakefulness is persistent without thought on any special topic, and that even when waking, the thoughts which crowd 


\section{Insomnia and Nerve Strain}

on his mind come later, gaining power gradually and only intensifying, not causing the condition. Even in so uncertain a science as medicine, the effect does not precede the cause.

The Fatigue Neurosis.-Neurasthenia in the wider sense is too indefinite a concept to discuss in detail. One of its prominent symptoms, however, fatigue, is common to many cases of protopathic irritation and should be distinguished from another result of such irritation, exhaustion.

The condition of a ganglion cell which has been irritated until incapable of further functional activity is one of exhaustion. This point may be reached either with or without fatigue which is a protective feeling inhibitory to the action of the cell. The normal feeling of fatigue is according to some authorities due to poisons which accumulate as waste products. As a result of muscular activity they are in and about the muscles, affecting the sensory elements. 


\section{Sleep and Fatigue}

Fatigue from mental activity can hardly be considered a toxic action on the ganglion cell itself but might conceivably result from toxic action on the smaller cerebral vessels.

However this may be, it is important to recognize the fact that fatigue often occurs practically without any exertion whatever. It may be from the action of extrinsic toxins carried in the general blood-stream and is one of the common phenomena of purely mechanical protopathic irritation. Dental caries and impaction, gastroptosis and the torsion of a movable kidney are frequent causes of the heaviness in the limbs as well as the thrills and wavy feelings so typical of the neurasthenic condition. This symptom may occur with insomnia or may alternate with it after the curious manner of rotation of protopathic symptoms in general. A further explanation of fatigue will be sought later in connection with other phenomena of action and reaction in the nervous system. 
48 Insomnia and Nerve Strain

\section{THE EMOTIONS}

Manic-DePressive Insanity. - Formerly all of the insanities more or less emotional in expression and not otherwise classified were included in mania and melancholia. The conception of the psychoses here presented is that they are due to a common set of physical causes, and merges all neuroses and psychoses as one essential process with infinitely varied results, like the harmonies and discords of a piano with one key-board and one performer. No essential difference in symptoms exists between the different psychoses, as they blend in infinite variety. Mania and melancholia are only somewhat more predominantly emotional than the others and the results of study of the emotions in these disorders are equally applicable to other members of the functional group.

Considering then melancholia and mania as the psychoses predominantly emotional, a study of their phenomena compared with the emotions which con- 


\section{The Emotions}

stitute so large a part of normal human activity develops the fact that no distinction can be drawn between normal and diseased emotion, that is emotion exists in absolutely unbroken series, from the lightest reflexes of a passing word or thought to the most profound result of the extremest physical or mental shock.

Physical Basis of the Emotions.The facts pertaining to the normal emotions are ably presented by William James in his Psychology. According to his view normal emotion, whether from physical or psychic causes, is always due to an altered visceral condition. A sudden noise or bright light or the sight of a revolver is the direct cause of the wildly beating heart, pallid face, motor unrest, and dilated pupils. The emotion is the cognition of these visceral changes. Apprehension of danger is not necessary to these phenomena, they may even appreciably precede the conscious sensation of fear. A man whose legs carry him off a battlefield finds that the faster he runs 


\section{Insomnia and Nerve Strain}

the more frightened be becomes. His motor energy and wildly beating heart intensify his emotion.

One of the best instances of what may be called the incubation period of the emotions is seen in the depression following a personal misfortune. Often after such an event there is for a time mental exhilaration, or an apparent numbing of sensibility occurs which may lead the subject to think that he is callous to the loss which he has experienced. There follow lowered heart action, a heavy feeling in the epigastrium, heaviness of the arms and legs, and a haggardness about the eyes which are readily apprehended as grief, and which in persons deficient in physical reactive power may persist even after the removal of the exciting cause.

Moods.-The emotions in lighter grade called moods have been considered by Head in connection with the referred pains which he has studied so thoroughly. Such moods may, however, be caused 
by visceral disease without referred pain, notably by the toxins of indigestion and malassimilation. A fermenting mass of food retained in the stomach may cause a simple depression, which it is quite impossible to shake off even though the cause is known, but which is promptly relieved by the use of the stomach-tube. Long-continued melancholy may be caused by deficient secretion of hydrochloric acid in the gastric juice, which is relieved by the administration of the acid.

In the mildest moods, the ordinary stronger emotions due either to psychic impressions or disordered viscera and even in profound melancholia or mania the emotion as it appears in consciousness is the result of visceral change.

Directness of Emotional Result.When, as is usually the case, the emotions are determined not by environment and circumstance, but are the result of a lesion, the ensuing emotion is as direct a sequence as is the pain of a burn or a pin- 


\section{$5^{2}$ \\ Insomnia and Nerve Strain}

prick. This is none the less true because these patients in thought project their emotions into causal relation with their circumstances.

PSychic PAIN.-The difference between ordinary pain as neuralgia, and emotional pain, psychalgia, is not great. Ordinary pain exists in consciousness as a percept of a destructive process in the periphery, just as a tactile sensation is a percept of contact in the periphery. Psychic pain is a percept of a destructive or calamitous process which may be located more or less dimly in the body as epigastric distress, a feeling of constriction about the heart or other organ, or it is perceived as a feeling of calamity without spatial relations, projected by intervention of the intellect into the external world of environment or circumstance. It follows from Head's later researches on sensation that true visceral pain, even when not translated into psychalgia, is sometimes apprehended as a pain or burning sensation definitely 


\section{The Emotions}

located outside the body, and this is much more true of the distinctly emotional sequences of visceral disease.

Contrast between Normal and AbNORMAL EMOTIONS.-There is no storehouse for emotions in the central nervous system. Memories are not in themselves emotional. They can only revive emotion by their effect on the viscera, an effect similar to that of the original psychic cause with ever weakening force as the memory grows dim. The continuing emotional result therefore of a grief, sorrow, or fear grows less apparent with each succeeding day. Memories weaken as present impressions grow stronger, and environment powerfully influences normal emotions.

Depth of Emotional Result. - In contrast with the normal emotions are the psychoses, which invariably have as their enduring basis a physical disorder. The patient with mania is taken from the scene of his work and from his home, 


\section{Insomnia and Nerve Strain}

torn from those he loves, imprisoned in a place naturally repugnant to him, often with food and surroundings not such as those to which he is accustomed. His emotional state, however, what the Germans more compactly term the Stimmung, is determined by his sickness, and fortunately for him it is joy. The melancholic is more often kept at home, surrounded by his loved ones, often given the delights of travel, soothed by music, and diverted in every way, but his emotion is determined by his illness. It is sadness so profound that these patients cut their own arteries, bite and swallow fragments from drinking-vessels, hack at their throats with jagged glass. No torment is for them too hideous to lend a terror to the approach of death.

It may be said in general that an emotional deviation from the normal which persists from day to day in the absence of an enduring psychic cause is invariably physical and the cause should be looked for in the viscera. The apparent persisting cause may be 


\section{The Emotions}

a memory either fabricated or true, but when memory does not weaken its endurance is the result, not the cause, of the emotional state.

Melancholia should not be apprehended as ganglionic sedation. It is the reverse of this, an agony so extreme as to be paralleled by no physical pain except possibly the most violent renal colic or gastralgia. The theory that mania and melancholia are identical but that mania represents a deeper grade of reduction is hardly tenable. The word reduction is misleading; the process in both instances is primarily an excitation, and mania in its milder forms is a trivial derangement compared with the profundity of the severer melancholias.

Mutability of the Emotions.-Although elation and depression are so different as to seem opposed, they do not neutralize each other like an acid and an alkali but mingle in consciousness like bitter and sweet; in other words we are dealing with a vital and not a chemi- 


\section{$5^{6}$ Insomnia and Nerve Strain}

cal phenomenon. In the easily excitable whether children or adults laughter changes to tears with proverbial quickness, and a sudden stimulus may provoke an emotion which may be termed pure excitement without being felt with deffniteness as either sorrow or joy.

When manic-depressive insanity occurs as the result of a tremendous event whether of joy or of sorrow, the psychosis takes color from the enduring antecedent emotional state, so that a sudden great joy is likely to be followed by a burst of tears and consequent melancholia. Disaster is in many instances followed by elation and mania.

So far as emotion affects purely mental activity, it may be considered as a force pulling on the intellectual content. Two such forces acting on the mind never pull away from each other but in lines that diverge at an angle. Here the analogy with non-vital energy ceases. The effect on mental inertia is to move thought and perception not on a line lying between the other two but to some 


\section{Subconscious Sensory Reflexes 57}

extent along each; in other words, and with another analogy, emotion is not a crucible for the fusion of thought but stimulates it to movement in many simultaneous ways.

\section{SUBCONSCIOUS SENSORY REFLEXES}

Sensory Manifestations in the Psychoses.-In considering pain it is possible to divide positive phenomena of that nature into extrinsic pains set up by an obvious external cause, and intrinsic ones, which arising in the body itself are sometimes in the locality of the cause, but are often due to a disorder so obscure or distant as to leave a doubt of the location and kind, even at times of the reality of the noxious agent. While the skin is the usual organ of perception of external objects and extrinsic pains the viscera have long been considered the main cause of intrinsic pains and their exploration in this relation is one of the ordinary subjects of medical research. 


\section{$5^{8}$ Insomnia and Nerve Strain}

The results in consciousness of protopathic excitation are not only pains, but also intense but vague feelings of discomfort, waves, thrills, and tense feelings in viscera, body, or extremities. The greater and more important part, however, of this process is subconscious, visceral function and mentality being alike more powerfully affected by the assaults of protopathic nerve waves below the level of consciousness, in a way comparable to the greater actinic power of waves beyond the violet end of the spectrum.

Excitants of the protopathic system may, however, affect epicritic nervous structures at the same time with distinct localizing pains as a result.

Protopathic irritation as it increases in intensity does not always cause greater pain. As a concrete example, dementia precox caused by dental impaction has almost the clearness of a laboratory experiment, as in it the severest symptoms are set up by the simplest irritant. Pains may be from beginning to 


\section{Subconscious Sensory Reflexes 59}

end quite lacking. Even the dull ache of protopathic irritation may be absent in the limbs, and salient features, such results of subconscious nerve-storms as the overpowering desire to escape, tearing out of hair, rocking to and fro, and continual moaning, are the symptoms attracting attention. When questioned these patients often deny any pain or discomfort whatever. Such actions, however, often follow the lines of referred pains and are not only significant of irritation but have a distinct localizing value.

In discussing the mode of action of the sensory system it is necessary as far as possible to consider pain as a valuable but rare indication; other sensory phenomena are obscure but common. The protopathic system as it exists in the more primitive forms of animal life is direct in its reactions. Motion follows directly on the stimulus. Epicritic function and thought do not supplant but are superimposed on the earlier forms of reflex and automatic reaction. They 


\section{Insomnia and Nerve Strain}

are switched in on the lower systems as a distinct afterthought and a protective mechanism which in man only partially replaces the lower ones.

Consciousness is in full relation with epicritic sensibility. We are adapted to know the outside world clearly, and ourselves as fountains of vague emotion and organs dimly perceived. The parts of our body clearly apprehended are not, our inner selves but our outer lines of communication with the environment. The organ of knowing is a thing apart. It is a protective mechanism of wider range, but more a matter of cognition and less of vitality.

Reference of Subconscious Pains.The dominant ego is usually a manifestation of subconscious nerve force. Some of the most marked and typical examples of such subconscious domination are found in dementia precox.

When irritation at the periphery causes a continuous current of nerve-waste from the basal ganglia lines of least resistance 


\section{Subconscious Sensory Reflexes 6I}

are occasionally set up from some adjacent sensory region, and the resulting discharge from that group of cells is apprehended as a pain, a feeling of oppression, or a vague distress. As neuralgia, headache, pressure at the nape of the neck, and other like sensory manifestations they are frequent in the psychoses, especially in melancholia and dementia precox. When intense they may be withdrawn from consciousness. Protective movements persist, however, as reflex or automatic actions of the kind previously mentioned. This occurred as a typical instance in Case $I 7$ of the present series.

One patient seen recently was profoundly melancholy for six or eight years, suicidal, and for the greater part of the time speechless. By continual effort the patient had pushed the upper front teeth backward at an angle of about forty-five degrees from the vertical. In this patient both upper and lower third molars were impacted on the left side. 


\section{Insomnia and Nerve Strain}

In another patient the subject of violent attacks of homicidal melancholia for the last twenty-five years and now for two years confined in one of the State Hospitals, the upper front teeth have been continually picked at with a pin through their whole length to the ends of the roots and so persistently that holes have been picked quite through them. The left second molar tooth has been picked out until it is nothing but a shell. Impacted against' this second molar tooth was a third molar, and no other molar teeth have been picked out except the one against which the impaction has taken place. When pain occurs as the result of the impaction of upper third molar teeth it is often in the adjacent second molars and runs forward along the jaw occurring in the front teeth. This patient denied pain in the teeth but picked at them with a dreamy faraway look as if the process gave her relief.

In a case of violent hebephrenia of six 


\section{Atavistic Symptoms}

or seven years' standing with the patient already somewhat demented, there has been in addition to beating the head against the wall and thrusting pins into the flesh a tearing out of the hair all over the head, especially over the left parietal region. This patient had an impaction of the left upper third molar tooth.

The occurrence of these subconscious sensory reflexes is most significant. Such acts furnish the dramatic element of insanity in the ordinary idea of the madhouse, although they may be quite lacking in cases of profound irritation. When present they have a distinct localizing value.

\section{ATAVISTIC SYMPTOMS}

Protective Flight.-When a caterpillar is touched it doesn't stop to look at the threatening hand but crawls away with tumultuous steps as if each segment were imbued with an especial and distinct desire to escape. In dementia precox 
64 Insomnia and Nerve Strain

the impulse to wander is an analogous phenomenon, not the presentation of a desire in thought but the vague compulsion of a feeling coming from an irritated periphery, a feeling of unrest that pervades the emotional field and in its severest form abstracts the mind from normal sentiment and intellectual activity.

Catalepsy.-Among the most striking symptoms of the psychoses, especially in severe cases of melancholia and dementia precox, are motor phenomena known as catalepsy and waxy rigidity. These rigid conditions are in no sense voluntary. Patients have been known to remain in the same position in a state of muscular tension for two or three years without themselves making any change. Such a feat is quite beyond the power of volition, and it may be doubted whether the cortical centres are capable of such prolonged effort even under the domination of the most powerful stimuli.

Protective rigidities of this kind are found in abundance among the lower 


\section{Atavistic Symptoms}

animals. Many insects seek to escape notice by rigid simulation of twigs and other inanimate structures. The truly cataleptic rigidity of the ordinary walking-stick and mobile rigidity of the praying mantis are evoked by protopathic stimulation. Some higher animals such as hares and deer are quiet so long as they think that they are unseen, and when it is obvious that they are discovered seek escape by protective flight.

The two most powerful emotions that come to the lower animals are the earliest prototype of fear and the desire for food. The reactions of the protopathic system to fear are seen in the rigidity as well as in the protective flight of the frightened hare, ferocity in the mobile rigidity of the mantis and the rush of the leopard. Physical manifestations of such emotions are present in the psychoses even when the emotions themselves are absent.

Fugues. - The longer and more fully developed examples of protective flight are called fugues. They are essentially 
66 Insomnia and Nerve Strain

irritative in origin and are especially apt to be evoked as are reflex pains by atmospheric conditions. They occur also in the lower animals, horses and cattle sometimes being known to drift for hundreds of miles before an oncoming storm.

Protective flight, fugues, and rigidity then as they occur in the psychoses may be considered as analogues of the same phenomena in the lower animals, and, as direct products of the protopathic system, should be differentiated from the motor results of delusions and other mental processes.

\section{DERANGEMENTS OF FORMAL THOUGHT}

DeLusions.-Of the symptoms of the psychoses, delusions are the most fortuitous. Their trend and existence depend more on the acquired than on the original portion of the apparatus of mentality, and in the milder cases they are in much greater degree subject to circumstance and environment than are 


\section{Derangements of Formal Thought 67}

the physical symptoms. The study of lycanthropy, folie a deux and in fact of almost any individual case shows that delusions like normal ideas are simply the attempts of the mind at interpretation of the perceptual material at hand. Ideas in the insane as in the sane take color continually from the inflowing perceptual currents, percepts of nerves of special sense blending with the mental content and being informed and colored by percept, sensation, and emotion from the viscera. Delusions are thus elaborations and effects of the lesion by indirection, not vital and scarcely integral parts of the disease-picture. In fact the solution of most of the problems presented by the psychoses lies in the study of the lower-level phenomena where brain and sympathetic system meet, and where it is doubtful whether one has to deal with mind at all as present in consciousness.

Ideated Sensations.-Many delusions may be considered as ideated sensations of 


\section{Insomnia and Nerve Strain}

touch, a phrase and idea borrowed from that most suggestive of art-critics Bernhard Berenson. In his recent book North Italian Painters of the Renaissance he gives a résumé of his earlier views on the sensory implications of Giotto's paintings important to the student of psychic values in relation to percepts of special sense as translated into terms of mind and emotion.

Origin of Delusions.-The mode of genesis of delusions in the psychoses will be apparent on consideration of protopathic influence on thought in general.

Thought is normally subject to volition as are speech and movements of the limbs, but is more mobile and elusive. At times with an inertia requiring much effort to overcome, sometimes, as for instance in insomnia, its near congener, mania, and many other conditions, it has compelling power practically irresistible. This is the case during protopathic stimulation, produced either physically or by means of ideated sensations. The 


\section{Derangements of Formal Thought 69}

result is thus identical whether from an impacted tooth, the ingestion of alcohol or what is called a stimulating environment, music, brilliant conversation or other like factor of emotion. Protopathic excitation, however, is capable when transmitted into other channels, of drawing attention and consciousness away from ordinary thought, impulsion being to certain limited fields, as for instance depressive memories. In an overwhelming tide of subconscious activity higher mentality may be submerged. This latter condition is one of pseudodementia.

Under protopathic stimulation sentiment and fancy are often quickened and thought finds readier expression than is usual. The effect on mentality may be desirable throughout the whole range of feeling. Whether formal thought is often thus stimulated is doubtful. That it may be much impaired even in the early stages of stimulation is certain. These circumstances of emotional and sensory domination over and weakening 


\section{Insomnia and Nerve Strain}

of formal thought are favorable to the growth of delusions which are common phenomena in the sane, and in protopathic insanity are not neomorphic but attempts at interpretation of endogenous feelings and emotions.

Thought then may be stimulated, weakened, or perverted by protopathic stimulation. Diversity of result in this domain as in those of sensation, motion, and emotion is not from inherent difference between the pathologic processes but is due to selective transmission of the resulting nervous discharge through various paths of least resistance.

\section{INDUCTIVE INHIBITION}

Anesthesia.-We are now ready to discuss the numbing of ordinary sensibility amounting to practical anesthesia which is so striking a feature of the worst cases alike of mania, melancholia, and dementia precox.

We may observe as a preliminary consideration that although epicritic sen- 


\section{Inductive Inhibition}

sation in the skin overbalances protopathic and is normally more vividly present in consciousness the protopathic system predominates throughout the body as a whole in size and vigor of action as well as in importance.

The infant is born practically devoid of epicritic function but soon attains to a fair amount of localizing information gained from all of the epicritic terminals. Protopathic information on the other hand remains incomplete throughout life, but may be added to from time to time. There is more individual variation in protopathic than in epicritic sensibility with regard to completeness, special viscera giving reactions of pain in some individuals and none at all in others.

The phenomenon observed by Head of excessive pain produced by stimulating skin supplied by protopathic but not by epicritic fibres may be explained by supposing that currents in the nervefibres are governed by the same laws with electric currents under the same circumstances. 


\section{Insomnia and Nerve Strain}

Such currents when passing in insulated wires generate in wires running parallel to them a current in the opposite direction on each closure of the circuit and a weaker current in the same direction on the opening of the circuit, so that the effect of an interrupted current is the increase of electric activity in the opposite direction in wires parallel to it. Nerveforce is supposed to flow in all three sensory systems in the same direction, that is centripetally; if so the effect of the action of any one system is to diminish the activity of each of the others. Thus each system is in a way regulated by the others.

\section{CONVULSIVE SEIZURES AND CHOREIC SPASM}

Mechanism of Sensation.-To understand even approximately the relation of structure with function in the nervous system a comparison is necessary, and only one is in any degree adequate, the time-honored one of an electric apparatus. 


\section{Convulsive Seizures}

Let us suppose then a battery of cells in the central ganglia and sensory nervefibres as wires coming in from the periphery. These countless distal signalstations must be provided each with a rheostat to account for the curious phenomena of irritation. Every one familiar with the water rheostat will realize that the carbon plates which when approximated allow the current to pass may easily be duplicates of the sensory end-bulbs; this is an explanation of the gradually increasing discharge in the basal ganglion cells determined by rising peripheral irritation. In fact the very circumstances and means of irritation are such as to suggest a similar or identical action. As an example a moderate poison swells the terminals or otherwise bridges the gap and allows the current to pass; or a severe toxin or heat which besides the swelling causes corrosion and thus closure of the circuit; or worst of all simple mechanical pressure, which as it persists and increases day by day never breaks but 
74 Insomnia and Nerve Strain

pushes the plates relentlessly together until the battery is fairly short-circuited; thus from renal torsion or dental impaction comes the terrible outpouring of energy in this or the other part of the ganglionic network as emotion, motion, or sensation, and then exhaustion which persists until pressure is relieved or death ensues.

A ganglion cell like a galvanic cell is active in inverse proportion to the resistance in the circuit, and the current set up by partial or complete closure at the periphery selects in passing in and from the ganglia lines of least resistance in both fibre and cell.

The theory of the neuron as a working hypothesis is here adopted, together with the generally received notions of the cortex as the principal seat of consciousness, and the basal ganglia, here used to include the spinal cord, as the location of reflex and subconscious motor and sensory nervous activity.

Location of Consciousness.-In or- 


\section{Convulsive Seizures}

der to an understanding of the reactions of the central and peripheral nervous mechanism to mechanical and toxic stimuli a brief consideration will be necessary of consciousness in its relation to the ganglionic masses, and of the familiar sensory and motor reactions to organic disease of the brain as well as to toxic agents.

It is generally agreed that consciousness is not a function supplied by a cerebral centre but is an attribute of the whole cortex, varying in intensity at different times and in different individuals and subject to a limited high-tension phenomenon variable through the whole field of consciousness, to some extent subject to volition, called attention. While attention is variable the comparatively mild and diffuse phenomena of consciousness go on so far as is known from birth to death, conditioned only on an activity of the cells in which they reside. When the activity of any of these cells is increased by stimuli from without or from other parts of the brain, con- 


\section{Insomnia and Nerve Strain}

sciousness becomes more intense, until a point is reached where attention is involuntary and compulsive.

The Cortex never directly StimuLATED. - Consciousness being thus directly variable with the activity of the cells we may inquire whether their phenomena may be produced by direct irritation. The fundamental proposition may be laid down that all stimulant action in the nervous system whether by mechanical agents, toxins, or organic disease is exerted on the basal ganglionic masses or peripheral nerve structures, never on the cortical centres. As applied to the neuro-psychoses it must at present suffice to examine the phenomena of epilepsy and chorea, in order to compare them in mode and place of origin with the psychoses under discussion.

The evidence is conclusive that the cortex may be experimentally cut, lacerated, and subjected to chemical irritation to any extent without being stimulated 


\section{Convulsive Seizures}

to activity of either its motor or sensory functions or to consciousness. This is also abundantly evident at operations on the cortex, the electric current being the only apparent stimulant, though irritants are many.

Epileptiform Convulsions. - The phenomena of the irritant action of brain tumors and other lesions are more complex. As a result of cortical disease convulsions are set up, sometimes of the common epileptic type, sometimes beginning in one group of muscles and spreading to others until they become general. A sensory aura is held to indicate an involvement of the sensory centres, the discharge beginning in the sensory cortex and spreading to the motor area.

That the centres of conscious sensory activity in the cortex are stirred to exaggerated action one after the other with the patient in profound unconsciousness is as near as possible to the unthinkable. There is here no question of exhaustion from over-stimulation, uncon- 


\section{Insomnia and Nerve Strain}

sciousness usually dates from the beginning of the attack and the centres resume their function a few moments after its cessation.

No Sensory or Psychic Epilepsy.It is further true that there is neither sensory nor psychic epileptic spasm corresponding to the motor convulsion. Such a paroxysm may be easily imagined. It would necessarily be terrible pain either involving successively one part after another of the sensory field, in fact a sensory Jacksonian spasm, or like a general convulsion, a sudden universal outburst. Instead of such a storm there is a light breeze, an aura, consisting of a tingling feeling, a flash before the eyes or other short-lived phenomenon ushering in a motor attack.

So-called psychic equivalents are in no sense epileptic outbursts of mentality. So far from being increments of intellectual energy they are characterized by diminution of consciousness much like that of ordinary sleep, as is indicated 


\section{Convulsive Seizures}

in their usual name, dream-states. In other words they are memories not evoked by the disease but modified by a partial withdrawal of consciousness.

The same reasoning has even more significance when applied to the centres for the storage of visual, auditory, and other memories. In the adult, memories are innumerable as the sea-sands, and their revival is only conceivable as occurring in consciousness and varying with consciousness. If a discharge were to sweep through this preponderating portion of the cortical gray, gathering force as it passed from ganglion to ganglion the resultant nerve-storm with its accompanying agony of heightened consciousness would compare with no convulsion of insentient nature but the awful majesty of the tornado. There is fortunately in human experience no such event as this. The brief sensory phenomena that usher in an attack are only such signals as may be sent in a moment and then the wires are down in the storm. 


\section{8o Insomnia and Nerve Strain}

Motor Convulsions never Cortical. -The consideration of motor phenomena in epilepsy is equally conclusive. Even a superficial comparison of the epileptic movements with action caused by normal discharge in the motor area of the cortex, shows the widest possible difference in quality. Epileptic spasm is not accompanied by nor caused by volition, it is not volitional in kind, being far removed from the delicate and complex movements due to activity in the co-ordinating centres, and when general and severe it is always accompanied by profound unconsciousness.

That the great voluntary co-ordinating centres in the cortex which energize the muscles are not roused to involuntary, unconscious, and inco-ordinate spasm is somewhat axiomatic in its obviousness.

Significant also is the fact that the speech-centre is never involved in convulsion and that disease of this centre itself never causes its epileptic discharge.

Lesser Attacks not Cortical.-In 


\section{Convulsive Seizures}

the case of epilepsy these facts find confirmation in the development of dementia due to exhaustion and finally permanent loss of function from overaction in the attacks. This loss of function finds expression mainly if not entirely in the subconscious apparatus of the intellect, and especially in the finer emotional adjustments which are of the part of the mental output called character. This corresponds with the fact that the so-called lesser attacks are the more destructive of mentality; these may be explosions of energy running like lightning through the subconscious intellectual apparatus at the base of the brain, a part of the nerve mechanism proverbial for its quickness of action, and meanwhile drowning consciousness, as is always the tendency of intense protopathic action.

Chorea.- - It may seem that as the cor-. tex is thus shown to be capable of stimulation only by signals of nerve force or its analogue in the outer world, electricity, 
82 Insomnia and Nerve Strain

cortical paroxysms might be set up by excessive stimuli coming from the sensory system. In fact this does occur. If we think of the necessary condition of manifestation of such paroxysms, it is evident that they must be conscious and co-ordinate, and the name applied to them is chorea. The closely allied habit spasms are often caused by peripheral irritants, and as choreic spasms are evidently cortical and cannot be caused by direct toxic action, the toxic locus morbi must be in the basal ganglia or periphery.

The sensory and mental phenomena occurring in chorea minor and itsanalogy with habit spasms make a protopathic origin probable. Organic cerebral disease associated with choreic spasm is usually situated in or near the great basal ganglia.

Mechanism of Epilepsy from CoRTical Disease.-All these phenomena lend color to the belief that in the basal ganglia the afferent sensory fibres are connected with the motor centres, as in 


\section{Convulsive Seizures}

effect they are shown to be by reflex phenomena, and that the motor centres are connected in series. Such an arrangement is necessary for ordinary combined muscular action, much of which must be provided for in these lower centres. The sensory centres on the other hand are not interconnected, one sense-impression rarely setting up a heterogeneous percept and such abnormal percepts never occurring in series. Such an arrangement furnishes the explanation of the single sensory and multiple motor discharge as a response to overstimulation. The explanation of so-called cortical epilepsy is in the degenerative process which is invariably downward from cortical disease. Fibres in both motor and sensory systems run in both directions and when degeneration sets up such irritation in the basal ganglia as to cause an epileptic discharge, it naturally begins in the structures corresponding to the cortical centres.

To summarize:-Epileptiform convulsions invariably consist in discharge of 


\section{Insomnia and Nerve Strain}

the basal ganglionic centres, and are determined in three ways: by irritation essentially degenerative downward from the cortex; by protopathic overstimulation up from the periphery; by toxins or disease acting on the basal ganglia direct. The two latter classes constitute the disease known as epilepsy, except for cases in which the cause is known, as for instance in those of renal origin.

\section{VASCULAR POTENTIAL}

The Vaso-neural Circuit.-When galvanic currents are applied to peripheral nerves it is found that centripetal currents increase and centrifugal currents diminish the activity of the sensory fibres. It follows that the normal sensory nerve currents are centripetal, and with equal certainty that the sensory is a oneway system. This means that with the battery in the central ganglia the peripheral fibre is connected with the negative pole of the cell, and the circuit must be completed through other tissues. As 


\section{Vascular Potential}

for the sensory and other cells not connecting with the periphery but with different parts of the brain there is every reason to think that they are run on the same system.

It is impossible that grounding should take place normally through the skin. The skin is often dry, practically a nonconductor, and usually in contact with the ground only through the soles of the feet.

The same reasoning applies with still greater force to the ganglion cells in the brain. The skull, skin, and hair are practically absolute insulators. Only one alternative remains. The circuit must be completed by way of the bloodstream.

Motor Nerve-Currents Are CentriPETAL. - In the motor system it has usually been taken for granted that the current flows from centre to periphery, that is centrifugally. We know, however, that normally cathodal closure contraction is greater than anodal closure 


\section{Insomnia and Nerve Strain}

contraction, that is the normal muscle reacts more strongly to the negative than to the positive pole of the galvanic current. This proves that the current of normal nerve-force in the motor fibres is negative, that is to say the motor like the sensory fibres are connected with the negative pole of the nerve-cells, and the positive current is in the bloodstream.

Inhibition by Vascular Potential. -Important conclusions follow. There is here an added reason for the balance between the epicritic and the protopathic systems in the skin. A stimulus in reaching the protopathic terminals from without inevitably excites the epicritic system. Both systems discharge their positive currents into the same bloodstream, and each positive current escapes into the blood less readily because charged from the other system. The same state of things obtains in the brain. Motor and sensory cells alike discharge their positive current in the blood, and unusual 


\section{Vascular Potential}

activity in any group of cells inhibits the activity of all the others by charging the blood-stream positively.

This makes possible a clearer concept of the self-limiting mechanism of pain. The sensory cells of the cortex are small and of comparatively low potential. High vaso-electric tension makes impossible their normal discharge into the vessels. When a stimulus, a burn for example, occurs over a small area of the skin the positive blood-charge is raised, but not enough to interfere with cellular action. If a large surface is burned, electric tension is raised to what may be called the anesthesia point, or with still greater tension unconsciousness may be caused.

It is difficult, in fact impossible, to carry on several lines of thought at the same time, although thought and speech are consistent with moderate activity in the motor centres of the arms and legs which discharge into the blood at some distance. It is doubtful, however, whether any one can carry on a sustained and 


\section{Insomnia and Nerve Strain}

difficult logical process while running at top speed. Inhibition by highly charged blood-currents finds its most striking example in the epileptic paroxysm, in which severe general convulsions so increase electric tension in the blood as completely to inhibit the sensory centres, and unconsciousness is the invariable result.

Paralysis by Anemia.-When the circulation is suddenly cut off from any part of the brain tissue by thrombus or embolism or in any other way the ganglion cells in the affected area instantly cease to act. This is not to be explained by the cutting off of their nutritional supply, which would begin to affect function after hours or days. Ganglion cells are set in a rich net-work of small blood-vessels. When circulation is cut off the blood at once leaves the small vessels and settles in the veins, the circuit is broken, and function ceases instantly, to be renewed if at all when circulation is re-established. 
Paralysing Effect of Cold.-The numbing effect of cold on nervous activity also here finds explanation. Ganglion cells and nerve fibres like the galvanic battery should work approximately as well when cold, which excites but never directly soothes nerve terminals. We find accordingly that cold as it stimulates the epicritic and protopathic end-organs acts as a tonic, and nervous energy is increased. When, however, it penetrates deeply enough to reach the vessels and so stimulate them contraction results, the part becomes bloodless, and the ordinary sensory rheostats are deprived of their connections with the main blood stream. Hence anesthesia results.

When the whole body is chilled for a sufficient time to lower the temperature of the blood and stimulate the small vessels about the central ganglion cells, they contract and the circuit is again broken, and anesthesia, unconsciousness, and finally paralysis and death ensue.

Vascular Potential as a Cause of 


\section{Insomnia and Nerve Strain}

Fatigue.-Fatigue is a phenomenon that may well occasionally bear an electric, not entirely a toxic, interpretation. After long ganglionic activity of any kind, sensory, motor, or mental, the bloodstream is highly charged positively. It requires more vigorous negative discharge to overcome the resistance. A bath, especially a hot bath with a following cold shock and reflux of blood to the skin, or massage, or the neutralizing and stimulating negative galvanic current, lowers positive vaso-electric tension and new energy may be tapped from the cells without undue effort.

Effect on Plain Muscle.-While striped or voluntary muscle is stimulated more actively by the negative pole, plain or unstriped muscle, as it exists in the blood-vessels, stomach, intestines, and other viscera, responds more readily to the positive pole. The phenomena of heart-action make it probable that this is also true of the heart muscle, which in structure seems to be half-way between 


\section{Vascular Potential}

the other two kinds of muscular tissue. The tendency then of a high vascular potential is to increase the activity of plain muscle throughout the body.

When a voluntary muscle is entirely severed from its connection with the cerebro-spinal system, it loses its tone, is reduced to the condition of a plain muscle, and gives corresponding reactions - that is, it reacts more vigorously to the positive pole and with a slow worm-like contraction. This, however, does not take place until about a week after the cutting of the nerve-supply - that is, until the degenerative process has had time to creep down and destroy the muscular end-plate.

Increased heart-action then and arterial contraction are set up by muscular exertion, emotion, excessive pain, or toxic irritation causing increase of vascular potential.

The effects of sudden raising of the potential of the blood-current on viscera supplied with unstriped muscle are well known. 'Thus increased gastric and intes- 


\section{Insomnia and Nerve Strain}

tinal activity, with vomiting or diarrhea, may be caused by emotion or pain, and action of the bladder may be induced in the same way.

EFfect on The IrIS.-A sensitive index of electric tension in the vessels, although not an uncomplicated one, is furnished by the iris supplied by radiating - that is, dilating-unstriped muscular fibres. The nearness of the eye to the brain gives cerebral activity a specially close connection with the pupillary reaction. During sleep vaso-electric tension is at its lowest and the pupil is contracted. Even slight mental energy dilates it a little. During waking hours it is of medium width, unless impact of light on the retina or toxic agents have affected it. It is dilated by unusual emotion or general physical exertion, and is widely dilated during the epileptic paroxysm.

Vascular Potential in Acute Shock. -Crile's brilliant researches have shown 


\section{Vascular Potential}

that shock is essentially a rapid exhaustion of the forces of the nerve centres. Acute shock may be defined as a sudden intense disturbance of the vaso-neural electric circuit. It may be caused by grounding the positive current in the blood-vessels, or by a short circuit introduced between vessels and nerves. From what has been said with regard to the reactions of the vascular system to the electric state of the blood, it must be evident that the calibre of the vessels will differ with the varying electric tension in these conditions.

The painful results of the short circuit are recognized in the popular dread of the knife as compared with the bullet. The slash is only painless when quick as light.

Shock might be largely avoided by insulated as well as by bloodless surgery; and the shock of bloody surgery is the shock, not of denutrition, but of lowered potential and a broken vaso-neural circuit. 
94 Insomnia and Nerve Strain

\section{MECHANISM OF THE VASO- NEURAL CIRCUIT}

Location of Closure of the Circuit. -To form an adequate idea of the complete mechanism of the vaso-neural circuit, it is necessary to consider ganglion cells with reference to the points of normal and abnormal closure. This has already been done in part with regard to the sensory system, the end-organs being rheostats for graduated closure of the sensory circuit, thus causing ganglionic discharge proportional to the amount of the irritation.

It is impossible that the motor circuit should be closed at the muscle. The motor ganglion cell is discharged as the result of a stimulus imparted to it in the central organs by a nerve fibre communicating with it indirectly. The cortical cells cannot be directly stimulated. They may be destroyed by any irritant that causes an internal short circuit. The only available explanation of the failure of direct stimulation is that the normal break in their circuit is in the basal ganglia. 


\section{Vaso-Neural Circuit}

Motility of Glia Cells.-The substance intervening between the inosculating processes constituting make and break is glia tissue. The glia cells, then, intervening between the dendrites of the motor cell and the vessels, or between inosculating processes of fibre and cell, respond to a stimulus from a sensory cell by a contraction which narrows and elongates them like an earthworm, and the connection is thus made. This endows the sensory system with motor functions exerted on the cells of the glia.

The fact that cells cannot be stimulated in the cortex makes consecutive combined movements impossible of cortical elaboration. On the other hand, simultaneous elaborations may be cortical, a single impulse from the base being diffused among a number of cells along lines of acquired least resistance of the intermediary glia cells.

The motility of the glia cells, then, like that of muscular fibre, is dependent on use, and ready and vigorous response to stimulation is in proportion to the 


\section{$9^{6}$ Insomnia and Nerve Strain}

amount of their previous exercise, especially recent exercise. Functional nervous disease owes what of permanence it possesses, apart from the persistence of the lesion, to over-developed glia cells constituting abnormal conducting paths, the glia cells resuming their normal size and activity gradually by rest after removal of irritation.

Pain not Cortical. - The fact that sensory cells cannot be stimulated in the cortex makes it certain that the stimulant closure of their circuit occurs lower down. This enables us to locate the function of pain. If it were registered in the cortex, closure of the circuit by basal disease would be excruciating agony. On the contrary, disease in that region is attended by numbness, tingling, and localizing feelings. Like emotion, pain is probably felt in the basal ganglia, and the point of its genesis by stimulation is lower down.

Ganglion Cells Nowhere Directly Stimulated. - This leads us to the broader statement that ganglion cells 
can never be directly stimulated either mechanically, chemically, or electrically. An electric current may be sent from a motor cell along the axis-cylinder process. Easily leaping the glia cell to the lower neuron, it stimulates the muscle. The effect of irritation in either of these three kinds on the ganglion-cell itself is an internal short circuit. The result is irritation with so-called sedation and final exhaustion.

The reason for the impossibility of discharging a ganglion cell by the direct application of electricity will be made clearer by the following consideration. Suppose an ordinary galvanic cell with the carbon and zinc attached to wires with terminations a sixteenth of an inch from each other and at some distance from the cell. Functional discharge of the cell is possible only by the introduction of a conductor between the ends of the wires. If the function of the system is to ring a bell on one wire situated on a loop beyond the break in the circuit, a connection made between the wires above the 


\section{Insomnia and Nerve Strain}

break will short-circuit the cell. Direct connection in the cell between carbon and zinc will result in an internal shortcircuit. If now the current from a dynamo be applied to the cell or to either of the wires, as a result the bell may be rung, the gap being ineffective for a current of higher potential. The only possible effect on the cell itself is a short-circuit.

The cortex, then, so far as it is known, is a power plant tributary to the main electric system of the base. It consists of batteries and storage batteries actuated entirely from below.

\section{NUTRITION AND VITALITY}

Trophic Control by Vascular Potential. - That vascular potential regulates trophic processes of the body in general is evident on the following consideration.

When a membrane is interposed between two compartments filled with fluid, with a negative electrode in one and a 
positive in the other compartment, while the current passes there is set up a flow of fluid through the membrane from the positive to the negative pole. These conditions are satisfied by both nerve cells and glandular cells all over the body. The limiting cell membrane separates the contained protoplasm from the positively charged blood stream. As electric tension rises, osmosis is more active; the whole glandular system is thus electrically stimulated by muscular or mental activity or emotion, in degrees varying inversely with the distance of the gland from the active nerve cells, and directly with the amount of their activity. Thus while nutritional and metabolic processes are under the direct electrical control of the nerve centres through the blood stream, the ganglion cells furnish alike the current of their functional activity and their own nutrition.

The gland cell, then, in its proper functional activity is an electro-chemic diffusion apparatus subject to control from a distance. Cell protoplasm 
100 Insomnia and Nerve Strain

apparently furnishes the negative electricity of the circuit, the nucleus being a positive element. This may well be the primordial apparatus of glandular activity, supplemented in the higher animals by vascular potential.

General Control of Nutritive ProCESSES. - What has been said with regard to glandular structures applies with equal force to the cells of the other tissues of the body. Thus nutritive processes vary directly with the general nervous activity of the moment, and with the richness of capillary supply, and inversely with the distance from the centres of greatest electric activity.

In the nervous system the protoplasmic processes are so numerous as to suggest that they provide for the nourishment of the ganglion cell, as well as closure of the current with the blood stream. During activity, osmosis is from within outward, the cell potential being necessarily greater than that of the blood stream. The result is the shrunken cell of fatigue. 


\section{Nutrition and Vitality IOI}

During rest, the potential of the cell is lower and osmosis is from without inward.

Nutrition of Muscle.-The problem of nourishment is somewhat different with regard to the three varieties of muscular fibre. The primitive muscle is the plain or unstriped variety. This is sluggish in movement, actuated by the positive charge of the blood stream, and draws its nourishment from the blood partly by its sluggish movements, partly by electric osmosis as do the glandular structures.

The heart is much more vigorous, is active from birth to death, and needs the maximum of nourishment, which is provided for by its own active movements, aided by its more permeable striped structure and by electric osmosis as well.

Voluntary muscle is striped to allow the maximum of nourishment during the activity of the muscle cell. If, however, osmosis went on uninterruptedly during rest, over-nourishment would be the result. The end-plate of the nerve, 


\section{Insomnia and Nerve Strain}

however, is on the outside of the muscle fibre and vaso-electric connection is with the interior of the cell. This reduces the difference between external and internal potentials to zero, and explains the rapid retrogressive changes from disuse.

When a peripheral nerve is cut, vascular potential falls in the supplied area either motor or sensory. The part is practically cut out of the electric sphere of influence of the body generally, and, as is well known, trophic changes result in all of the tissues.

\section{CELL POTENTIAL IN EVOLUTION}

A consideration of vascular potential in its developmental relationsmay beof value, as a basis for further investigation.

In unicellular organisms specialization has just begun, and is comparative with non-vital substances. The power of assimilation, of sensitiveness to impact, and of comparatively purposive movement are acquisitions. The specific dif- 
Cell Potential in Evolution I03

ference, however, from non-vital matter is the ability to maintain nutritional interchange with environmental substances by means of a difference between intracellular and extracellular potential. This is made possible by electric activity between nuclear and extra-nuclear protoplasm, the evolution of the cell with its nucleus being the anatomic attribute, and electric osmosis the physiologic attribute of vitality in primitive organisms.

Physical osmosis by capillarity and by contractile movements, and osmosis by differences of density are non-specific acquired powers.

With the acquisition on the part of the cells of more complex animals of highly specialized powers, in the glandular tissues metabolic power, in plain muscle contractile power, and so on, there is in most tissues retention of specific electric function in the same sense; that is, the maintenance in cell protoplasm of negative potential as compared with extra-cellular and intra-nuclear positive potential. 


\section{I04 Insomnia and Nerve Strain}

In the evolution of the ganglion-cell and the correlated striped-muscle tissue, a specific difference from lower grade tissues is introduced.

The structure of the ganglion cell indicates the electric continuity of the axiscylinder process with the nucleus, and of the protoplasmic process with the cell body. We have already seen that the axis cylinder is connected with the negative, and the dendrites with the positive pole of the cell. This is the reverse of the formula of polarity of the lower tissues.

In striped muscle, by the electric connection of the blood stream with the interior of the cell, there is no difference of potential between cell and blood, and osmosis is not electric, but only mechanical and chemical.

The specific difference, then, between ganglion cells and lower cells in general is in the reversal of polarity; the distinguishing feature of striped muscle is the neutralizing of polarity.

Nutritive processes go on in ganglion 


\section{Epicritic Neuro-Psychoses 105}

cells practically only during rest, in striped muscle practically only during activity; while in other tissues functional and nutritive processes are alike practically continuous, being less active during sleep only by reason of the lowering of vascular potential.

Vitality may be said to consist in the ability of an organism to maintain a difference of potential sufficient to carry on nutrition by electric osmosis. It is a power inherent in most or all cells and specialized in the ganglion cells.

The conclusion seems warranted that nerve force and electricity are related by identity rather than by likeness.

\section{EPICRITIC NEURO-PSYCHOSES}

Hysteria.-Of the lesions thus far considered, neuroses and psychoses alike are primarily lower-level disorders, and in them the cortex is implicated only secondarily. There remains one of the most complex of the functional disorders and one which has long been the 
Io6 Insomnia and Nerve Strain

subject of careful study, namely, hysteria. Its symptoms, while often disturbances of vegetative life, concern themselves about equally with the emotions and with the perceptive functions and highest mental activities of the cortex, consciousness, attention, and volition. The shortest possible statement must here suffice of the hysteric symptom-complex in its relations with the nervous mechanism.

The characteristic feature of the hysteric symptom-complex lies in the ease of conjunction and disjunction of the ganglionic centres, both conscious and subconscious, together with abnormal activity of the centres.

It is not necessary to suppose unusual power on the part of the ganglion cells themselves. There is rather an unusual completeness of connection of the vasoneural circuit as well as between the nerve centres, with correspondingly rapid exhaustion of nervous energy. Volition and self-consciousness have an undue share in the abnormal condition, and are worthy of special consideration. 


\section{Epicritic Neuro-Psychoses Io7}

Self-consciousness is the highest application of formal thought to the processes of ideated sensation and vivified idea, resulting in cognition of mental personality, distinguished from physical identity, as a partly inherent, partly habitual mode of operation of percept and thought in a special and delimited nerve-mechanism.

A voluntary act is one to whose production the highest mental functions, consciousness and formal thought, have contributed. Volition so far as it exists within the limits of cognition is a feeling of freedom of choice and to a greater or less degree a feeling of effort accompanying certain conscious movements of the soma, operations of the psyche, and selective movements of attention.

Certain limitations of the will are subjectively recognized, comprising acts carried out by the lower motor centres, thoughts that seem to come into the mind spontaneously and attention compelled by sensation overmastering 


\section{Io8 Insomnia and Nerve Strain}

memory and thought. The dominance of ideated sensation is also subjectively recognized, either as the spoken word compelling and determining ganglionic activity, or the power of circumstance acting through consequent emotions. It is this dominance of ideated sensation in either of its forms that, normally present in all men, when abnormal in degree is the essential feature in hysteria.

Motility of the Glia in Hysteria.Predisposition to hysteria consists in an original or acquired ease of disjunction of certain paths of communication between cortex and basal ganglia. The hysteric may thus be capable of mental activity of high grade, but has an instability between conscious and unconscious mentality. Hysteric symptoms result from shocks or suggestions breaking the connections just mentioned. It is apparent that hysteria has affiliations with both hypnotism and ordinary sleep.

Umusual activity of association between percepts and memories on the one hand, 


\section{Epicritic Neuro-Psychoses Iog}

and the protopathic system on the other, brings the hysteric into strong touch with the wills of others, and the result is a protopathic system dominated. In the genius, in whom the power of concentration is unusually developed, the intrinsic faculty of formal thought is stronger.

Clinically hysteria may be provisionally defined as a state of abnormally heightened consciousness subject in unusual degree to abstraction from certain fields and increased attention to others under the influence of protopathic and epicritic forces alike extrinsic and intrinsic. The diminution and heightening of activity in the cortex result in nerve currents which follow the lines of least resistance, in the higher psycho-motor centres, or downward to the sensory and emotional mechanism of the base. Unusual length and motility of the glia cells such as are here supposed explain the equal susceptibility of hysteric subjects to psychic and physical shocks.

It is easy to see that when disjunction occurs from concussion or from a strong 


\section{Io Insomnia and Nerve Strain}

sensory impression, physical recovery of the glia may in time be practically complete, and a mental impression be at last the means of forcing a current through the re-established pathway.

Disjunction then in the hysteric may be a local phenomenon resulting in anesthesia or paralysis, or approximation of the mobile glia may result in hyperactivity either motor or sensory. More general disjunction, especially by hypnotic suggestion, may plunge the hysteric into sleep at times profound, but, like ordinary sleep, consistent with the maintenance of certain communicating paths and much cortical activity.

I am inclined to class hysteria tentatively as an epicritic disease. Its symptoms are largely in the epicritic field, voluntary convulsions, spurious coma, and imitative diseases. Its precipitating cause is often epicritic, either ideated sensation or the spoken word. Its cause may be protopathic, as the exciting cause of protopathic disease may be epicritic. 
Hallucinatory insanity and paranoia are epicritic in manifestation. I have made no observations in regard to the location of possible irritants in these cases. Provisionally they may be classed as epicritic psychoses.

\section{PROGNOSIS}

In the preceding sections we have gone far by deduction to gain some idea of nervous interaction. Such considerations are of moment in proportion with their ultimate bearing on the concrete phenomena of disease, and hope of cure.

The outlook for recovery from any disease is in proportion not only with the chance of spontaneous removal of irritation and nutritive repair, but with the possibility of aiding these processes on a basis of adequate diagnosis.

Among the diseases here set down there is one that has no single redeeming feature. Many epileptics have long intervals of normal activity; maniacs have the joy of their disease; the demented 


\section{I1 2 Insomnia and Nerve Strain}

have at least euphoria, lapsing with the revolving years into the final mercy, euthanasia; but a little melancholy is a little curse and a great melancholy is torture indescribable. Of this one disease, subjectively at any rate the worst of all, it may be said that it is often not only recoverable but curable, absolutely and by procedure. This follows from the many cases of recovery prompt on the heels of definitive protopathic relief. Most of these patients are permanently cured, the earliest of those here set down being at this writing well for fifteen years and more.

In regard to mania, indications by analogy and direct experience supplement the present recorded cases and indicate the same result of cure. The same may be said even of dementia precox.

Patients apparently demented for years, the cog-wheels of the memory to all appearance thrown permanently out of gear, often finally rouse and return to normal life. Noteworthy is the fact that most of the patients studied by 


\section{Prognosis}

Kraepelin in his great work on Manicdepressive Insanity, and scheduled by him as hopelessly demented, eventually recovered after many years. The number of memories in use by an individual at a given time is almost infinitesimal compared with those that are inactive. Attention may be withheld from any group of memories by the activity of attention given to another group, or may be abstracted from the higher memories entirely, by abnormal activities in the protopathic structures at the base. That on the recovery of protopathic health memory is regained is in accord with what we know of facts relating to memory in other conditions.

The number of spontaneous or rather accidental recoveries recorded from time to time have been enough to indicate the possibility of a lesion curable if found. Significant lesions in abundance have been already found by skiagraph in many of the cases here described and indications of more are to be had for the seeking. The lesions have been 


\section{4 Insomnia and Nerve Strain}

removable, and analogy with the results attained in other groups of cases beats a broad path of probability of a successful issue here also, to measures thoughtful in their adequacy and vigorous in execution.

Of insomnia it may be said that it is a symptom, the most tractable of all, whether it goes hand in hand with mental aberration or in association with the mildest indications of the neurosis of fatigue. This tractability is, however, absolutely conditioned on removal of continuing irritations.

The other diseases under consideration are known to be curable in varying proportion, the more if their cause is known.

\section{THERAPY.}

The neuro-psychoses are in part toxic in origin. To understand the symptoms and the methods of their cure it is necessary to consider in brief the rationale of the selective action of poisons on 


\section{Therapy}

the nervous system, especially the alcohols, ethers, and alkaloids.

DRUg Action. - Two striking and recently observed instances of such selection are the local anesthetic effect, which really means the peripheral anesthetic effect of cocain, and the comparative actions of the sulfonal group, practically pure hypnotics, and of the antipyrin group, practically pure sedatives of pain.

The effect of the latter group on temperature is too obscure for present consideration and will be ignored. A comparison of the developmental reasons for the differences between their actions and those of the alcohols and ethers gives a clue to the location and probable reason for the location of action of these several toxic substances.

The lowest animals to develop a heart. with a nervous mechanism of stimulation were small creatures and soft, penetrable throughout by the ordinary products of 


\section{Insomnia and Nerve Strain}

fermentation and decay, alcohols and ethers. Their life depended on the development of nervous tissue resistant to the sedative action of these substances; such resistance is not absolute but exists to a comparatively high degree. Later respiration was developed, aërial and aqueous, carried on by a nervous mechanism of somewhat feebler resisting power. The general protopathic system, the penalty of whose temporary sedation is not the instant death of the whole organism, became endowed with a selective resistance. The deeply situated ganglion cells are less resistant to the sedative action of these omnipresent poisons. The end-organs, whose usefulness lies in their excitability, are stimulated alike by wounds, heat, pressure, even by these erstwhile toxic sedatives.

The later epicritic system, with its receiving centres in the cortex and signalstations in the skin, presents a curious deviation from the action of its protopathic relative. The action of the alcohols and ethers on the cortex is surely by 


\section{Therapy}

sedation, or what is the same thing, irritation and consequent exhaustion.

The fact that the active principle of the leaf of one plant and that of limited habitat, the erythroxylon coca, should have the unusual power of sedation of the sensory terminals, shows that the resistance of these to the early sedative power of alcohols and ethers is a protective acquirement, the unfit having early perished by intoxication.

Purely artificial products of the laboratory, such as the anilin derivatives, form a class by themselves. Their only evolutionary relations are by indirection through their similarity with natural products. Accordingly the known sedatives epicritic by preference are few; that is, the drugs with the function, useless in nature, of soothing the cortex before acting on the lower centres are antipyrin, phenacetin, and other similar products of the laboratory. The sulfonal group, on the other hand, are first of all protopathic sedatives. They are powerless to 


\section{Insomnia and Nerve Strain}

control processes of cognition, either of nerve pain or genuine mental distress. The vague activities that bring insomnia and melancholy out of the subconscious ego they may quiet, and this they do first.

This leads to the final generalization in regard to drug action. Drugs in so far as they affect nerve tissue act on it invariably by irritation, as do mechanical agents. Some nerve tissues are awakened to functional activity by such action, in others that activity is impeded by the irritation, this constituting socalled sedative action. The difference between stimulation and sedation is the difference between closure of the circuit and short-circuit.

This is not to say that either an internal or external short circuit of a ganglionic battery may not under some circumstances be beneficial. Its conditions of usefulness are problems alike for the pharmacologist and clinician.

Counter-IRritants and Diffuse 
IRRITANTS. - In treatment it should ever be borne in mind that results are not simply in quantitative proportion to the nerve flow. Disaster, when not due to an overwhelming quantitative loss, usually comes from high-tension escape from a single point, or escape at a point where undesirable lines of least resistance have been established.

High-tension escape may be controlled or alleviated by ordinary counter-irritation or by diffuse irritation.

One of the most efficient means of distributing irritation generally over the protopathic terminals, thus lowering tension and diminishing loss at a special point, is by the use of alcoholic drinks. As alcohol produces at some times elation and at other times depression, and the tendency in psychic cases is to excess, with consequent over-stimulation and eventual visceral disaster, its use should be discouraged as dangerous.

A safer method is by laxatives. Protopathic intestinal activity tends in 


\section{20 Insomnia and Nerve Strain}

general to euphoria, largely by the elimination of irritant poisons.

If irritating, however, laxatives, like other protopathic stimulants, quite rarely produce melancholy instead of elation.

In case of either mania or melancholia, in fact of any neuro-psychosis from a local protopathic irritant outside the gastro-intestinal tract, a laxative relieves by the counter-irritant action of the diversion of sensory nerve-currents. In case of nervous symptoms from intestinal stasis, laxatives relieve by removal of the irritant poisons. These various phenomena may in part account for the well known clinical fact that purgation is good for almost anything; it is in fact the great protopathic regulator.

Purgation is, however, not available indefinitely. Stomach and intestines finally rebel. The skin is a more patient organ, and a seton may be efficient after years of useful activity.

Climate and Baths.-General stimulation of the skin not only diminishes 


\section{Therapy}

protopathic strain, it induces widespread epicritic activity as well. Not only such measures as hot and cold baths, the salt glow, and the electric-light cabinet have this effect, but a sojourn in some land of sunshine keeps the skin stimulated, especially if the clothing be light-colored. This is an expedient to be used with caution in cases of nerve strain. Tension is taken off for a time by the continuous flow of nerve currents in the skin, but this relief is later succeeded by exhaustion.

The diffuse nerve flow for a time removes fatigue and gives a sense of vigor, as does a salt rub or a hot bath. Not under control like ordinary therapeutic measures, motor exhaustion and sensory irritability are apt to ensue in the neurotic and finally even in those tolerably strong, with insomnia, which may indeed be an early symptom.

In the tropics even more than in sunny lands like Arizona, conditions favor nerve flow, and with very different results. 


\section{Insomnia and Nerve Strain}

For instance at Singapore where the thermometer never goes above eightyfive and the air is always near the dewpoint, with almost one hundred per cent. of contained moisture, languor and exhaustion are so great that it is dangerous to walk abroad in the middle of the day, and sunstrokes are frequent. This difference from Arizona, where with a summer heat of $I 10^{\circ}$ or $I I 5^{\circ}$ sunstroke is unknown, is striking. The clinical thermometer does not show that in the drier climate body heat is kept lower by evaporation. Nerve waste, however, proceeds on very different lines. The moist skin freely taps the comparatively deep potential of the blood stream through a skin constantly soaked by the saline product of the sweat glands.

The use of baths should be governed by the capacity of the individual to react. This depends on the integrity of the vaso-motors, and this again largely on the degree of their protection by fat. In thin people undue contraction of the vessels occurs, and vascular potential 
is rapidly lowered, with consequent exhaustion.

Suggestive Therapy.-In civilized man the spoken word affects the protopathic symptom powerfully for both good and ill. Suggestive therapy is usually powerless to affect a protopathic system stimulated and attention diverted by a severe physical irritant. The wide application, however, and generally beneficial effect of this form of treatment in its various modes of application are well recognized in combating the annoying and disabling symptoms of the moderate cases.

Physical disorders lie especially open to the action of faith and argument, and the mysterious but familiar powers of an extrinsic personality. Pain may be overcome, confidence restored, vitality stimulated.

The mentally afflicted, however, meet persuasion with argument, they beat down hope with despair, and in the worst cases oppose to all psychic measures 


\section{r 24 Insomnia and Nerve Strain}

the impenetrable defence of a soul withdrawn and inaccessible.

Intensive Treatment.-The maximum effect on disease is attained by primary eradication of the cause and simultaneous moral uplift and general improvement of physique. The improvement attained by one of these means alone increases in geometric ratio with the addition of the other two.

The most brilliant plan of treatment in this wise is Dr. Weir Mitchell's rest cure. By his device forced feeding builds up the insulations of the brain and cord and surrounds the terminals of the skin and the subcutaneous vessels with non-conducting fat. Massage and electricity ensure enough discharge both motor and sensory to keep nerve tension low. Isolation prevents psychic shocks; a cheerful nurse to read to the patient and otherwise divert him prevents the nerve-waste of fretting and homesickness, and Dr. Mitchell's own patients have the uplift of his commanding personality. 


\section{Predisposition and Heredity 125}

\section{PREDISPOSITION AND HEREDITY}

Predisposition to Nervous Disease. -The neuro-psychoses in general may be defined as conditions of nerve waste from excessive irritation, usually protopathic, accompanied by phenomena of disordered nerve action. The particular phenomena are determined by lines of original or acquired least resistance in the nervous system and may be sensory, motor, or psychic.

Neurotics are those in whom protective insulations have been more or less weakened or broken down. The neurotic tendency is constituted by original weakness of protective insulations or acquired abnormal activity on the part of the connecting glia.

So far as predisposition to the neuropsychoses is nervous, it manifests itself in two ways; by unusual sensitiveness to the action of irritants, shown by undue sensory and emotional reaction; and by unusual susceptibility to exhaustion from 


\section{I26 Insomnia and Nerve Strain}

consequent overaction. Patients in whom the first kind of predisposition predominates are prone to mania, melancholia, and various neuroses; those in addition readily exhausted develop terminal dementia or dementia precox.

Delicacy of emotional reaction can hardly be considered degenerate. It is in no sense atavistic, being conspicuously absent in the lower races, and is rather a mark of the finer adjustment to his environment characteristic of civilized man, than of a return to a lower and coarser type.

There is another mode of nervous reaction that may be considered degenerate, the reaction of too great resistance. Robust persons may be nervously so immune to toxins as to suffer corrosion and sclerosis from suppurative or alcoholic intoxicants, ending in death, with no nervous reactions to indicate its approach. A railroad with red lights so delicately set as to flash out on the 


\section{Predisposition and Heredity 127}

rumble of every passing cart might be said to suffer from over-refinement in its signal department. It would, however, have advantages over a road with signals still dark and the train in the ditch.

Neuro-Psychoses not Degenerate. -In the matter of the significance of the so-called stigmata of degeneracy it is interesting to study the countenances of one's friends. There may be noted among them the occasional irregular teeth, slanting Mongolian eyes, asymmetric faces, adherent ear-lobes, and all the other signs and omens. Confront these physical conditions with their mental and moral qualities. The upright mind, level head, kind heart, and playful demeanor are amply compatible with what are called the physical attributes of degeneracy. In the asylums note that insanity is like sanity impartially distributed among people with and without stigmata.

The idea suggests itself that a stigma 


\section{28 Insomnia and Nerve Strain}

becomes important in the etiology of insanity only when it is at once a stigma and a lesion, as is the case with an impacted tooth. This being granted, the explanation of heredity of the neuropsychoses is at once in hand. They are hereditary as headaches are hereditary, never by the symptom but by the visceral lesion, the sagging kidneys, inactive stomach, astigmatic eyes, crowded or impacted or decayed teeth. The symptoms follow according to the pathologic equation of the individual as headaches, habit spasm, epilepsy, melancholy, mania, or in presence of the tremendous irritation of impaction, even dementia precox.

Predisposition, then, to the neuropsychoses is of two kinds, nervous and visceral. Nervous predisposition consists in weakness or irregularity of the insulating tissues, or more often an overdevelopment of glia cells with resulting abnormal paths of communication, and may be either hereditary or acquired. Visceral predisposition consists in proneness to 


\section{Predisposition and Heredity 129}

visceral disease, and may be either hereditary or acquired.

There is a distinct value which may attach to the materializing tendency of the theory now advanced. Whatever may be thought of the inner meaning of the so-called physical stigmata, there is another stigma adherent to insanity, the odium of a disease that brutalizes and that flows to posterity through the blood. If it can be shown that this heredity is not a slimy ancestral current descending to engulf the soul, but something limited and palpable, no worse a blemish than a tumor or a gangrene, something will have been done in the asylums for the comfort of those who wait without the walls. 


\section{APPENDIX \\ DENTAL LESIONS}

$\mathrm{O}^{\mathrm{F}}$

F the viscera responsible for the more obscure cases of nervous and mental derangement I have no hesitation in designating the teeth as the most important. This is not only on account of the common, almost universal occurrence of dental diseases, but because these organs move, during the period of their development, through the solid framework of the jaw, highly innervated and clothed by a membrane sensitive to impact and to corrosive toxins.

The two most important lesions, impaction and abscess, are both of them in some cases obvious to inspection, but usually they can only be discovered by skiagraph. Impactions may be in any region of the jaw. They may be indicated with some probability by a gap 


\section{32 Insomnia and Nerve Strain}

where the missing tooth should be, but such a gap is by no means conclusive. An extraction may have been made and forgotten, or teeth fail to develop, leaving a gap or a temporary tooth persistent sometimes for years.

The presence of all the teeth in their proper place is not conclusive against impaction, as is shown by an occasional fourth molar.

Inspection is in many cases inadequate to show abscess at the roots of a tooth. In some cases the pus finds its way out between the tooth and the gum, but abscesses may persist for years, undermining mental health or physical strength, without pain or other localizing sign of their presence.

The skiagraph is only capable of showing absorption of bone, and pus may be present for a time without this, but in most cases within a few weeks or months after development of an abscess the skiagraph shows in the negative a dark area of absorption. The germs find their way to the roots of the tooth, usually through 



\section{Appendix}

the pulp chamber, as a result of decay, but may be carried by material used in filling the root canals. Abscess sometimes develops, however, about a tooth dead though not decayed.

A distinction should be made between an alveolar abscess and an ulcerated tooth. When an abscess at the root of a tooth follows the peridental membrane to the surface and involves the soft tissues, the tooth is popularly said to be ulcerated. This is a comparatively harmless process, as pain and swelling make the difficulty an obvious one. With the evacuation of the pus the soft tissues recover but the abscess remains in the bone, noxious but inevident.

The object of dentistry is the conservation of the tooth, for mastication and ornament. Dead teeth were formerly filled, the main pulp chamber being plugged and the roots left open. It was found that abscess was practically invariable in the course of some years at the roots of such teeth. Modern practice is 


\section{I34 Insomnia and Nerve Strain}

to fill dead teeth to the end of the roots, as nearly as may be.

To estimate the proportion of success and failure of this procedure it will be necessary to consider in brief the course of events in these cases. The process is in effect a battle between the germs and the blood. The germs, practically always present in spite of the greatest care and skill, march down the hollow of the tooth by multiplication, often requiring several years to cover the distance to the end. Once out of the opening and in the jawbone they are like a squad of soldiers with their backs against a wall, the forces of serum or white blood cell can only attack in front, with an effectiveness diminished by half, and even if successful for a time more germs are always lurking in absolute safety in the dead tissue of the tooth.

If to prevent this condition filling material is pushed to the end of the root and a little of it forced through into the jaw, an irritant is in contact with the tissues, and in most cases germs accompany it. 


\section{Appendix}

If, on the other hand, it falls a thousandth of an inch short of the opening, the tiny germs find ample space for lodgment.

A man is as old as his arteries, and his arteries are approximately as old as the combined action of suppurative and other toxins has made them in the preceding years. Oral sepsis is not all superficial. Its most important location is usually deep in the jaws. In probably no other part of the body can purely irritative lesions be studied in contrast with suppuration and toxemia and the symptoms of each condition followed with accuracy. Impactions result in pure irritation, dental caries in irritation with a minimum of toxemia; abscesses begin in irritation, and result when large and multiple in profound chronic intoxication.

The brilliant and rapidly developing technique of dentistry has as its object the preservation of the teeth for the natural mechanics of mastication. " $\mathrm{Ne}$ l'arrachez pas" is the dental watch-word 


\section{36 Insomnia and Nerve Strain}

in this country even more than in France. The preservation of dead teeth is of doubtful value. Suppuration may occur about well filled teeth, and even about teeth that are unfilled and undecayed. It is almost inevitable about bad teeth, and the one sure method of treatment is extraction, which may, however, in many cases be reserved until after the trial of conservative measures.

The ominous conjunction of multiple abscesses with the triad of cardiac, renal, and vascular disease is one that has been casually noted in several of the cases reported in this series and some others. To exclude suppuration as a causative factor in these cases skiagraphs are absolutely necessary.

Many other lesions are potent in causing irritation. Fillings which encroach on the soft tissues or bone are often revealed by the skiagraphs and so remedied. I am unable as yet to give any estimate of the importance of pulp 


\section{Appendix}

nodules. It is only possible for me at present to make the broad general statement that irritation and septic poisoning should be removed in every case, and that local results of dental lesions are trifling in comparison with their profounder effect on general health.

In studying skiagraphs the original negative should always be employed. Much detail is lost in printing. The best results in the diagnosis and treatment of cases dependent wholly or in part on dental disease are to be obtained only by the co-operation of the physician and the dentist. Skilful reading of skiagraphs on the part of the physician is absolutely necessary; all of the teeth in both jaws must be shown to the ends of the roots.

I wish to express my thanks to Dr. C. H. Clark, of the Cleveland State Hospital, Dr. H. C. Eyman, of the Massillon State Hospital, and Dr. George Stockton, of the Columbus State Hospital, for their courtesy in allowing me to observe the patients under their care. 


\section{38 Insomnia and Nerve Strain}

I am indebted to Doctors J. F. Stephan, E. B. Lodge, and J. W. Van Doorn for much aid in dental matters. It need hardly be added that the writer is alone responsible for the opinions here set down. 


\section{THE TECHNIQUE OF DENTAL SKIAGRAPHY}

By Dr. E. Ballard Lodge, Cleveland

THE peculiar anatomical conditions of the maxillæ and the teeth render their examination by Roentgen rays satisfactory only when skiagraphs are taken by placing the sensitive film or plate within the oral cavity. A skiagraph taken through the maxilla or the mandible with the plate placed opposite causes not only a distortion and lack of fine definition but also a duplication of the shadows which render the resulting picture vague and difficult of interpretation. The writer's method for obtaining skiagraphs of the teeth and adjacent tissue is to make use of small plates or films, preferably the latter, protected from light and saliva as follows.

Two Seed's Process Films $1 \frac{3}{4} \times 1 \frac{1}{4}$ inches are wrapped in two folds of photographer's 


\section{Insomnia and Nerve Strain}

black paper. The ends are turned to the side opposite the chemical side of the films and pasted down with a piece of suitable paper. The films may now be taken to the light without danger of fogging. Next enclose the envelope in a small aseptic napkin such as is made for dental use, six inches square. This is to prevent the corners of the envelope from irritating the tissues. The ends are folded away from the chemical side of the film. Having done this, wrap the whole in a small piece of dental rubber dam five inches by two inches. This is stretched and holds to the corners of the package if tightly drawn. The rubber is particularly necessary in taking lower teeth to protect the films from moisture. The package is now placed within the mouth and in contact with the lingual surfaces of the teeth, the patient being directed to hold it in position by the finger. It is important to place the edge of the film parallel to the occlusal or incisal alignment, and the chemical side toward the ray. 


\section{Technique of Dental Skiagraphy I4I}

The adjustment of the tube varies for different parts of the jaws. The ray should always strike the film or plate at right angles to a plane midway between the film and the teeth. In the molar and bicuspid region of the upper maxilla, the elevation of the tube with reference to the teeth should be from forty-five to fifty degrees above the horizontal. In the incisor or cuspid region, the tube may be somewhat higher than this.

In the case of the lower molars and bicuspids, the ray should be horizontal so that it will strike the plate at right angles, because in this instance it is possible to place the film or plate parallel with the long axes of the teeth. In case the film is not held in a vertical position but inclines away from the teeth at its lower edge, it then becomes necessary to lower the source of the ray or to elevate the patient so that the ray emanates from a point a few degrees below the horizontal, to compensate for this deviation from a parallel position. 


\section{Insomnia and Nerve Strain}

With the lower incisors it becomes necessary to direct the ray thirty to forty-five degrees upward in order to get a skiagraph that will not be greatly distorted. This is because the film cannot be placed with its lower edge close to the teeth. The anode is placed at an average distance of ten inches from the teeth and the time of exposixe is about seven seconds.

Unless the angle of incidence of the ray is carefully calculated, there is apt to be either a foreshortening or an elongation of the shadow. 





\section{Univerelty of Calliomia SOUTHERN REGIONAL LIBRARY FACILITY 405 Hilgard Avenue, Los Angeles, CA $90024-1388$ Return this materlat to the library from which it was borrowed.}

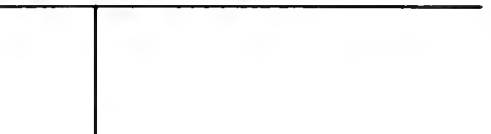


RC 002 . US,

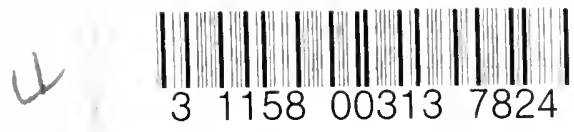

UC SOUTHERN REGIONAL LIBRARY FACLLITY

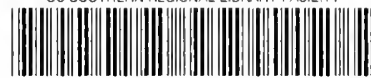

A $001377142 \quad 3$ 
83,

3) fitit?

n?

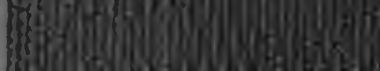

36.

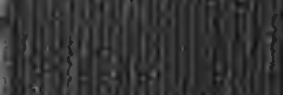

(28)

(a)

(3)

60 and

a.d.

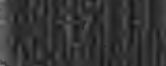

3.

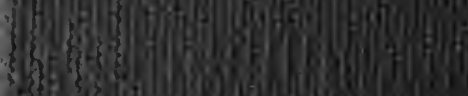

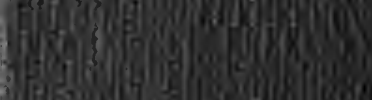

3.

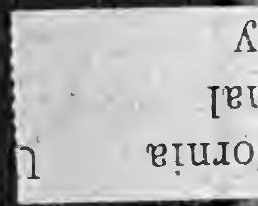

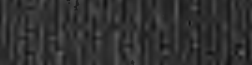

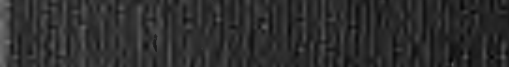

8.

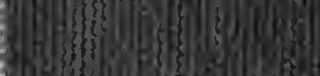

1.

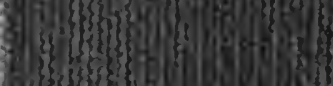

Las\}?

3.

dastoms.

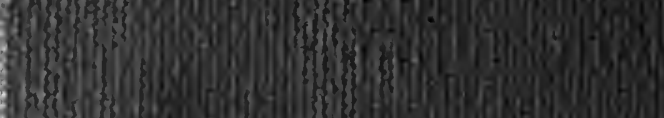

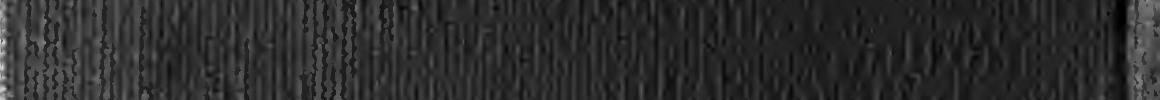

